\title{
Experimental and Numerical Study of Boundary and Anchorage Effect on Laminated Glass Windows under Blast Loading
}

\author{
Xihong Zhang ${ }^{1 *}$, Hong Hao ${ }^{2}$
}

1.School of Civil, Environmental and Mining Engineering, the University of Western Australia, 35 Stirling Highway, Crawley WA 6009, Australia

\author{
2.Tianjin University and Curtin University Joint Research Center for Structural \\ Monitoring and Protection, School of Civil and Mechanical Engineering, Curtin \\ University, Kent St., Bentley WA 6102, Australia \\ *email: xihong.zhang@uwa.edu.au
}

\section{Abstract}

Over the years extensive studies have been conducted to analyze the response of laminated glass panes under blast loading for personnel and property protection. The failure modes of glass windows in most of those studies are related to flexural bending of the glass panel. The problems of laminated glass failure at boundaries along window frames, as well as the influences of window frame constrain effect and the interlayer anchorage on the overall response of laminated glass panels are less examined. In this paper, experimental and numerical studies are carried out to examine the boundary conditions and interlayer anchorages of laminated glass windows on their responses under blast loadings. Blast tests were designed and conducted on window specimens with different frame bite depths, fixed or sliding boundaries and different interlayer anchorages. Numerical model of laminated glass windows is also developed. The accuracy of the numerical model in prediction of glass window responses is verified by field blast testing results. The validated numerical model is used to perform intensive simulations to study the window boundary conditions and interlayer anchorage measures on glass window responses to blast loadings. The results demonstrate that properly designed window frame and interlayer anchorage will increase the survivability of laminated glass windows under blast loadings.

Keywords laminated glass, field blast test, numerical analysis, anchorage 


\section{1. Introduction}

2 Tragedies related to the hostile terrorist bombing attacks and accidental explosions

3 are occasionally reported as news headlines throughout the world, e.g., the recent

4 fuel tank explosion in Nanjing, China in June 2014, and the terrorist bombing attack 5 in Oslo, Norway in 2011. Most post-event investigations of such incidents have cited the majority of human casualties and injuries were rather than by the air blast wave or the bomb container fragments themselves, but mainly by the shattered glass windows, fragments of walls and other objects which were not secured and were propelled towards the residents by the blast waves $[1,2]$. Due to its relatively weak strength, glass windows in such incidents are especially fragile, and consequentially lead to enormous casualties. For better human protection against blasting loads, the development of blast-resistant windows has been being research topics of many researchers, manufacturers, security personnel and government officials all over the world.

Different techniques and materials are available to provide blast resistant glass windows, which include replacing low strength annealed glass by high strength thermally tempered glass or by laminated glass. Lin et al. conducted an intensive review on available window strengthening solutions [3]. Recent field blasting tests on monolithic glass windows found that by using thermally tempered glass, the blast resistant capacity of the glass windows can be effectively improved [4]. However, under large magnitude blast loads monolithic tempered glass windows rupture into numerous jagged shards which impose significant threats to the residents [5]. Employing laminated glass panel for windows has proved itself through experiments and experiences of explosion incidents to effectively mitigate the risks of human injuries from ejecting glass fragments. Laminated glass consists of two or more glass plies bounded together by polymer interlayers such as Polyvinylbutyral (PVB) or SentryGlas ${ }^{\circledR}$ Plus (SGP, ionoplast produced by DuPont ${ }^{\mathrm{TM}}$ ) of different thicknesses. After glass crack under blast loading, the polymer interlayer will hold the glass splinters and continue to deform substantially as a membrane. In such a manner, the imposed blast energy will be dissipated by the laminated glass panel through large deformations. 
The failure process of a laminated glass pane under blast pressure can be divided into the following five steps: (1) the entire laminated pane deforms elastically; (2) cracks are formed on the outer glass ply under tension; (3) cracks extend and occur on the inner glass ply; (4) the interlayer retains the cracked glass plies and continues to deform; (5) Rupture is formed on the interlayer. Zhang et al. studied the failure modes of laminated glass panes through numerical simulations [6]. It was found that if the laminated glass pane is clamped firmly, shear failure occurs on the interlayer along the boundary when it is subjected to impulsive load with significant reflected pressure in short duration; flexural bending failure is expected when it is under relatively long duration loading; and a combined shear and flexural failure will be formed on the PVB interlayer if it is under intermediate dynamic loading. Parametric studies have been carried out to study the influence of glass thickness, interlayer thickness and glass strength, etc. on the failure modes of glass panes [6, 7].

In analyzing the response of laminated glass windows to blast loads, the influence of boundary conditions is found to be significant. Larcher et al. [8] modelled a $1.0 \mathrm{~m}$ $\times 0.8 \mathrm{~m}$ laminated glass panel with different boundary conditions, i.e. fully fixed boundary, in-plane sliding boundary which restricted glass pane longitudinal movement in the direction of blast wave but allowed in-plane transitional sliding, and elastic boundary to model the supporting rubber strips between frame and glass. The numerical results showed the glass panes with different boundary conditions responded quite differently. A largest pane central deflection was found on the window with sliding boundary, while a smallest central deflection was resulted on the window with elastic boundary. A larger central deflection is more likely to cause interlayer rupture, which means the laminated pane with in-plane sliding boundary can be the most fragile. In Zhang et al.'s pressure-impulse analysis on $7.52 \mathrm{~mm}$ thick laminated glass panels, the ultimate load bearing capacity of the laminated pane with pinned boundary was found to be about $15 \%$ more than that with fully fixed boundary condition [7]. By reducing the rotational restraints along the window boundary, a more flexible window system was achieved which exhibited better blast 
1 possibility of adjusting the boundary conditions to further improve the blast resistant capacity of a laminated glass panel.

3 The ideal failure mode of laminated glass windows discussed above is not 4 necessarily always achievable. In Hooper et al.'s full-scale field blasting tests on 5 laminated glass windows [9], before tearing occurred on the PVB interlayer, the entire cracked laminated panes were pulled out of the window frame and pushed into the occupied area behind the windows. In other words, the failure of the window was mainly due to joint failure at the window boundary rather than the failure of the laminated glass pane itself. The bite depth, namely the embedment depth of the glass pane into the window frame, is believed to play an important role in the overall response of the laminated glass windows in face of blast loading. Morison mentioned that for laminated glass with $1.52 \mathrm{~mm}$ thick or more interlayer a 25-30 mm deep bite is required to achieve the better blast loading resistance [10]. Laboratory tests and field blasting tests on laminated glass panels reported recently provide more insights to the influence of window bite depth. For instance, Kranzer et al. [11] tested $7.52 \mathrm{~mm}$ thick laminated glass panels fully clamped in $1100 \mathrm{~mm}$ by $900 \mathrm{~mm}$ steel frames with $50 \mathrm{~mm}$ bite depth. No boundary failure was observed on any of the four tested panes. In the airbag pendulum impact tests by Zhang and Hao [12] carried out on $600 \mathrm{~mm}$ by $600 \mathrm{~mm}$ laminated glass (various thicknesses) with $30 \mathrm{~mm}$ bite depth all around, pane slipping out of the frame was not observed either. These tests on laminated glass windows indicate that a properly designed bite depth is needed to prevent premature failure of pulling the laminated pane out from the window frame before the interlayer ruptures so as to achieve the full blast loading resistance capacities of the laminated glass panes.

To prevent the potential slippage failure along window boundary, interlayer anchorages have been introduced to stop the laminated panes from being easily pulled out of the frame. For example, in manufacturing laminated glass panes tails of PVB interlayer are left perimetrally along the pane boundary, which are then clamped into the window frame to provide certain anchorage. Fixture bolts can also be applied along the frame at specific spacing, which further anchors the PVB tails to the window frame. Another measure introduced by US Air Force Research 
1 Laboratory is called mechanical fixture bar method [13]. This method uses a doubly

2 laminated glass pane which consists of three glass plies and two PVB interlayers. The

3 ends of the PVB interlayers wrap around steel rods which are firmly mounted into

4 the wall. When the laminated pane is under lateral loading, the steel rods will hold

5 the PVB interlayers and stop the laminated pane from being pulled out of the

6 window frame. The efficiencies of all these strengthening techniques have been

7 proved individually by their respective developers, mainly by field blast tests.

8 However, performance of the respective strengthening techniques applied to

9 windows other than those tested are not clear. The advantages and disadvantages of 10 each individual measure over the other are not known either. Therefore, study and

11 analysis on these anchoring measures for general window systems are needed.

In this study, full-scale field blast tests were carried out on $7.52 \mathrm{~mm}$ thick laminated glass panels fully clamped by two robust steel frames with $50 \mathrm{~mm}$ bite depth all around. The blast pressures and the responses of the laminated panes were recorded by pressure sensor and mechanical Linear Voltage Differential Transducers (LVDT). High-speed cameras were used to assist monitoring the response of the panes with pre-plotted tracking dot matrix. A doubly laminated glass panel installed in an innovative sliding boundary frame system was also tested in comparison with the one installed in the fully fixed boundary frame to examine the performance of the proposed sliding boundary system in mitigating the blast loading effect. Numerical models of laminated glass were developed and calibrated with field blast testing results. Numerical simulations were then conducted to investigate the influences of boundary conditions, namely the fully fixed or sliding, bite depth, and the interlayer anchoring methods on responses of laminated glass windows to blast loads.

\section{Experimental Investigation}

\subsection{Description of experiment setup}

In the current work, laminated glass panes were tested with different weights of TNT at various stand-off distances in six shots. A reinforced concrete (RC) frame of approximately $3.4 \mathrm{~m}$ by $3.2 \mathrm{~m}$ by $2.0 \mathrm{~m}$ (width by length by height) as illustrated in 
1 Figure 1 was constructed with deep rooted independent footings to support the

2 glass window specimens for the test. The testing block consisted of two individual

3 cells. The back wall of the block was left open for high-speed cameras to monitor the

4 deformation of the glass panes. In each shot, two glass panes were tested with

5 designed charge detonated in front of the RC block. The glass window specimens

6 were installed on the openings of the front wall using steel frames. The laminated

7 glass panes were $1.5 \mathrm{~m} \times 1.2 \mathrm{~m}$ in dimension. For the first five tests, the laminated

8 panes constructed with two plies of $3 \mathrm{~mm}$ thick annealed glass sandwiching a

$91.52 \mathrm{~mm}$ thick PVB interlayer (Figure 2a). These five $7.52 \mathrm{~mm}$ laminated glass panes

10 were tested in pair with another five glass panes of the same sizes but different glass

11 and interlayer thicknesses. The responses of the other five glass panes were used to

12 evaluate other issues therefore not included in this article. The tested laminated

13 glass panes were firmly clamped with steel frames as illustrated in Figure 3a. The

14 window frame, as shown, consisted of a $20 \mathrm{~mm}$ thick inner frame, which was fixed 15 onto the front wall of the RC block using M24 bolts. The testing panes were placed 16 on the inner frame, and then covered with a $10 \mathrm{~mm}$ thick outer steel frame. The 17 outer frame was fastened with care onto the inner frame using M12 bolts. Torque wrench was used to ensure an equal compression was applied to glass pane through these M12 bolts. During installation, plastic strips were inserted in the gaps between the inner and outer frames to avoid damaging glass pane when fastening the bolts. There was no clearance gap left between glass and the window frame. In this manner, a fully fixed boundary condition was created for the laminated glass windows to be tested. The bite depth of the frame is $50 \mathrm{~mm}$. No silicone or epoxy was squeezed between glass and the frame. Therefore there was no epoxy bond at the interface.

Besides the $7.52 \mathrm{~mm}$ laminated glass panes described above, two doubly laminated glass panes which comprise of three layers of $6 \mathrm{~mm}$ annealed glass sandwiching two 1.52mm PVB interlayers (Figure $2 \mathrm{~b}$ ) were also tested in pair to examine the effectiveness of a sliding boundary over the traditional fully fixed boundary for mitigating glass window damage to blast loads. In the test, one glass pane was supported with the fully fixed boundary as described above and another 
1 one with the sliding boundary. As shown in Figure 3b, the sliding boundary frame consisted of the same inner and outer frames as in the fixed condition. An extra thick layer of plastic pad was placed in between the two frames. The testing glass panes were inserted into the gap and rested against the outer frame. After fastening the M12 bolts, a 50mm sliding distance was created for the glass panes to move freely in the direction of blast wave. When the blast wave acts on the windows, the laminated panes is able to slide in the direction of loading to mitigate part of the shock wave energy, which will reduce pane deflection, as well as the pulling out potential of the laminated pane from its frame. Using a doubly laminated pane instead of the single laminated one in this test is to increase the stiffness and strength of the glass pane, so as to avoid immediate pane failure before it slides. Therefore the effectiveness of using sliding boundary can be examined in the tests. It should be noted that in the current test, the glass pane was placed in the sliding boundary without any support. In practice, however, some elastic material with small stiffness might be used to support the glass pane, which will make the glass pane not exactly free sliding. Therefore the effectiveness of allowing glass pane to slide freely for blast energy absorption might not be fully achievable in practice.

The targets of the experimental tests are to measure the laminated glass pane deflections under different blast loadings, to monitor the failure process and to study the failure modes of the laminated panes at joints with window frames. A pressure transducer was installed on the front wall of RC block between the two glass windows to measure the blast pressure. LVDTs were fixed onto two steel frames behind the windows inside the RC block to record the central displacements of the glass panes. The transducers were wired through an amplifier to a portable data acquisition system, which was setup dozens of meters away and hidden behind a concrete bunker. The sampling frequency for data collection was set to be $0.5 \mathrm{MHz}$. Two high-speed cameras (Fastcam SA3 Photron ${ }^{\circledR}$ ) were placed at an angle behind each window outside the RC block, and were protected by two heavy steel bunkers. An 11-row by 9 -column black dot matrix (100mm spacing) was plotted on each laminated glass pane before the test. With the tracking dot matrix, the two highspeed camera images could also be used to monitor the deformation and response 
1 of each glass pane. The filming frequency of the high-speed cameras was setup to

$2 \quad 2 \mathrm{kHz}$. The aperture of the lens and the exposure time were adjusted accordingly. In

3 each test, the high-speed imaging process and the data acquisition for pressure and

4 displacement were triggered by signals from external wires glued directly onto the

5 charge.

6 Table 1 lists the information of the laminated glass panes presented in the 7 current study. It should be noted that a total of 13 blast trials were carried out. This paper devotes to examining the influences of boundary conditions on laminated glass windows. Therefore only test $1,2,3,4,6$ and 7 were presented here. In the first three tests (test 1-3), the $7.52 \mathrm{~mm}$ laminated panes were fully instrumented with measured reflected pressure histories, central displacement histories, and recorded high-speed images. The recorded pressure and pane central displacement histories will be later used to validate the numerical model described in this paper. For test 4 and 6, reflected pressure histories and the failure processes of the laminated panes were recorded. The failure modes of the laminated panes were used to analyze the influences of bite depth on window responses under different blast loads. The doubly laminated pane with sliding boundary was tested together with another identical pane with fixed boundary condition in test 7. LVDT was not installed in this test to avoid damaging the sensors owing to pane sliding. However, the responses were captured by the high-speed camera images.

\subsection{Testing results}

The experimental results from the full-scale blast tests are presented in this section. The recorded blast loads, glass pane failure processes, pane failure modes, and the central displacement histories are provided and analyzed.

\subsubsection{Blast loads}

The primary charge for the current tests was Trinitrotoluene (TNT). The TNT explosives were casted into cylinders with desired weights. A $5 \mathrm{~cm}$ diameter hole was left in the centre for the RXD booster charge. Electric detonators were inserted into the axis of the booster charge. Figure 4 shows the reflected pressure recorded by the 
1 pressure transducer for the first three tests (1-3). The time axis is aligned to the

2 instance when shock front arrived at the glass windows. As shown in Figure 4a, in

3 test 1 the detonation of $10 \mathrm{~kg}$ TNT at $10 \mathrm{~m}$ away resulted in substantial reflected

4 pressures (about $121 \mathrm{kPa}$ ) which dwindled to ambient quickly. Long duration

5 negative pressures followed, which attenuated gradually. Table 2 summaries the

6 reflected pressures recorded for both the positive phase and the negative phase. The

7 recorded reflected pressures are integrated along the time axis to derive the

8 reflected impulses. Estimations using Kingery-Bulmash equations are also provided

9 to demonstrate testing consistency.

\subsubsection{Displacement histories and failure processes}

Figure 4a-c show the glass pane central displacement time histories recorded by the LVDTs on the three $7.52 \mathrm{~mm}$ laminated panes in test 1-3 together with their applied reflected pressure histories. For instance, as shown in Figure $4 \mathrm{~b}$ the glass pane in test 4 responded to the air blast wave with a relatively gradual increase in its central displacement initially. As glass plies cracked, the central displacement began to increase quickly with a steeper slope over time. The interlayer membrane still held the cracked laminated glass pane together. A maximum deflection of about $320 \mathrm{~mm}$ was reached, after which the pane began to rebound. The measured displacement history ceased soon after it rebound because the probe of the LVDT debonded from the cracked glass ply.

Figure 5a shows the snapshots of high-speed camera images from the $7.52 \mathrm{~mm}$ laminated glass pane in test 4 . As shown, the laminated glass pane deformed under the air blast pressure and the back glass ply cracked at $2 \mathrm{~ms}$ (at $\mathrm{t}=17 \mathrm{~ms}$ ) after the shock wave was applied onto the window. The pane reached its maximum deflection at $25 \mathrm{~ms}$, after which it began to rebound. The cracked laminated pane was pulled out along its boundaries during rebound at $t=35 \mathrm{~ms}$. At $\mathrm{t}=55 \mathrm{~ms}$ the laminated pane was totally pulled out of the frame. Figure $5 b$ shows the high-speed camera images of the laminated pane in test 1 . As shown, the laminated pane reached a maximum deflection at about 30 ms or about 15 ms after the blast wave arrived at the window which is consistent with the LVDT recording as shown in Figure 4a. The cracked 
1 laminated pane rebounded, but joint failure did not occur. At $134 \mathrm{~ms}$ the pane was still firmly clamped in the window frame without any sign of joint failure. It is to be noted that in test 1 the aperture of the high-speed camera mismatched with the light. As a result, over exposure occurred when the overwhelming light from detonation made glass crack not visible initially. Nevertheless, the high-speed camera images still provided information on how the laminated pane responded during the blast. The high-speed camera images show that both panes in test 1 and 4 survived the positive phases of the blast load, the maximum deflections were reached without boundary failure, but the laminated pane in test 4 was pulled out of the window frame during rebound possibly due to the sustained negative pressure.

\subsubsection{Failure modes}

Figure 6 shows the failure modes of the tested $7.52 \mathrm{~mm}$ laminated glass panes after the blast tests. It can be observed that glass plies of all the tested windows were badly shattered, and larger blast load leads to more severe damage of the same glass window as clearly observed in the damaged pane 3-1-1 with $\operatorname{Pr}^{+}=82 \mathrm{kPa}$, and pane 1-1-1 with $\operatorname{Pr}^{+}=121 \mathrm{kPa}$. Moreover, PVB tearing was found on the laminated pane 1-1-1, but not in pane 3-1-1. Both panes remained in the window frame without boundary failure. Partial pulling-out failure was observed on pane 6-1-1 under increased blast loading. As shown, this laminated pane was partly pulled out of the window frame along its two vertical and bottom boundaries. The pulled-out part of the laminated pane was outside the window frame facing the explosion centre, indicating the pane was pulled out during rebound by the negative phase blast pressure. Total pulling-out failure was found on the other two laminated glass panes, namely pane 2-1-1 and 4-1-1 owing to larger blast loadings in these two shots as given in Table 2. As shown in Figure $6 \mathrm{~d}$ and e, the laminated pane was totally pulled out of the frame, and left on the ground in front of the window, indicating again the action of the negative phase blast pressure. The high-speed camera images shown in Figure 5 a illustrate the pulling out process during the laminated pane rebound. 
None of the $7.52 \mathrm{~mm}$ laminated glass windows tested in the current blast trials experienced large interlayer tearing. In fact the interlayer still held most of the cracked glass fragments, indicating great performance of the PVB interlayer in mitigating the blast loading hazards from glass fragments. However, as shown in Figure 6, the cracked laminated glass panes could be partially or totally pulled out of the frame, which also imposes significant threats to people in the vicinity. The observed pulling-out failure was possibly because the glass in contact with the steel window frame was damaged during the positive blast loading phase owing to large blast pressure and window deformation. The crushed glass layer inside the frame resulted in a loss of contact of glass pane with the window frame. Therefore the glass panes were pulled out during the negative blast loading phase. Since falling glass pane is also hazardous and should be avoided, it is therefore important to understand such damage modes at the glass pane boundary and properly design the anchorage and window frame to prevent the pull-out damage of laminated glass windows under blast loading.

\subsection{Comparison with previous testing data}

The blast testing results presented above show that laminated glass pane could be sufficiently strong to resist blast loadings. In such cases, the damages related to glass fragmentation and PVB interlayer rupture do not occur, but damage at the glass pane boundary might happen that results in the pulling-out of glass pane from the window frame. To further examine this possible damage mode, previous field blast testing results on $7.52 \mathrm{~mm}$ laminated glass windows conducted by other researchers are collected and analyzed in this section.

As mentioned above, Hooper and his colleagues tested $1.5 \mathrm{~m} \times 1.2 \mathrm{~m}$ laminated glass with $25 \mathrm{~mm}$ embedment [9]. Four blast trials with blast loads from various combinations of C4 charge weights and stand-off distances were conducted. Among Hooper et al.'s four tests, one laminated pane at the $152 \mathrm{kPa}$ peak reflected pressure and $461 \mathrm{kPa}$-ms reflected impulse was considered severely damaged because the cracked laminated pane was totally pulled out from the clamping frame along all four sides and pushed into the testing room (Figure 7b). In comparison, pane 2-1-1 in 
1 the current blasting test was subjected to blast loading of similar magnitude

$2(\mathrm{Pr}=169 \mathrm{kPa}, \mathrm{Ir}=476 \mathrm{kPa}-\mathrm{ms})$, and pulling-out failure also occurred along the window

3 boundaries. However, as described above and shown in Figure 7a, instead of being

4 pushed into the testing cell, the laminated pane was pulled out of the frame and

5 sucked out of the testing cell. Comparing the recorded reflected pressure with that

6 in Hooper's test, the current test has a slightly higher blast pressure and impulse.

7 The high-speed camera images show that the glass pane survived the positive

8 pressure phase, but was pulled out from its frame during the negative pressure

9 phase. The reason for these different failure modes is probably due to the larger bite 10 depth of pane 2-1-1 in the current study. Compared to the $25 \mathrm{~mm}$ bite depth in 11 Hooper's test, the $50 \mathrm{~mm}$ bite in the current specimen provided greater resistance to 12 hold the cracked laminated pane sliding into the room during the positive blast 13 pressure phase, although the gripping effect of the frame bite was weakened as 14 friction between glass and steel strips degraded when cracks extended through the 15 glass in contact with the frame. On the other hand, as demonstrated by some researchers that larger pane deflection could be expected when the effect of negative pressure is superposed with the rebound of the laminated pane [14]. The amplified deflection during rebound led to the laminated pane being pulled-out of its frame in the current tests.

Figure 8 summarizes the maximum pane central deflections of laminated glass windows with different bite depths under various blast loadings obtained in the current study and reported by other researchers in literature. The reflected impulse is used as $\mathrm{x}$-axis to show the magnitude of blast loads. Considering window size differences, the reflected impulses are normalized against window size (the square root of window area). In the x-axis, $a$ and $b$ stand for window length and width respectively. In Figure 8, the solid symbols indicate the tested panes failed with joint 27 failure, while the open symbols represent those without joint failure. With $25 \mathrm{~mm}$ 28 bite depth, the four $1.5 \mathrm{~m}$ by $1.2 \mathrm{~m}$ laminated panes tested by Hooper et al. had a small bite over pane width ratio of $25 \mathrm{~mm} / 1200 \mathrm{~mm}=0.021$. Under $461 \mathrm{kPa}-\mathrm{ms}$ reflected impulse, the laminated pane was pushed into the testing cell with joint

31 failure because of the insufficient anchorage of the pane in the frame. Another pane 
1 tested in [9] also experienced severe damage along its boundary when it was

2 subjected to $391 \mathrm{kPa}-\mathrm{ms}$ reflected impulse, but was not completely pushed out of its

3 frame owing to the restraints at the four frame corners. In the current field blast test, 4 with $50 \mathrm{~mm}$ glass embedment into the frame, it had a higher bite depth over window 5 width ratio of $50 \mathrm{~mm} / 1200 \mathrm{~mm}=0.042$. The deeper bite provided higher anchorage 6 against pulling-out failure. As shown above, under 395kPa-ms and 413kPa-ms 7 reflected impulses, the laminated panes in the current test were firmly restrained in 8 the frame despite large pane deformations. When subjected to higher blast loadings, 9 i.e., $476 \mathrm{kPa}-\mathrm{ms}$ reflected impulses, the $7.52 \mathrm{~mm}$ laminated pane failed along its 10 boundaries and was forced out of the window frame. However, due to the restraint 11 effect of deep bite, this pane survived the positive phase blast loading, but was 12 pulled out of the window frame during rebound. Kranzer et al. [11] also provided $1350 \mathrm{~mm}$ bite to the laminated glass panes in their experimental tests of smaller 14 window specimens of dimension $1100 \mathrm{~mm} \times 900 \mathrm{~mm}$. Because the ratio of bite depth over window width was higher $(50 \mathrm{~mm} / 900 \mathrm{~mm}=0.056)$, in their blast tests, all four laminated panes were firmly held by the rigid window frame. No joint failure was

17 found among the tested panes. Through the above comparison it can be concluded that bite depth to window dimension ratio plays an important role in preventing joint failure. Depending on the bite over pane width ratio, as well as the blast loading amplitude, the laminated glass window joint failure might happen although the PVB interlayer could survive the blast loads and keep the shattered glass fragments together. The failed window joints may result in the window pane being pushed into the room or sucked outside by the negative blast pressure. It is therefore important to properly design the anchorage to prevent the joint failure of laminated glass 25 windows.

\section{Numerical Simulation}

27 To further investigate the effectiveness of glass pane anchorage on preventing joint 28 failure of laminated glass windows, a three dimensional finite element model of 29 laminated glass window is generated using the commercial software LS-DYNA. 30 Detailed laminated glass windows including the steel window frames as described 
1 above in the field tests are modeled numerically. The model is calibrated with field

2 blast testing results. Extensive numerical simulations are then carried out with the

3 verified model to study the influence of bite depth, and different interlayer

4 anchoring retrofit measures on preventing joint failure.

$5 \quad 3.1$ Model description

$6 \quad 3.1 .1$ Model configuration

Figure 9a depicts the typical finite element model of the laminated glass panel with fully fixed steel frame. 8-node solid elements are adopted to model the windows. Each node has six degrees of freedom. Full integration is utilized. The laminated pane is $1.5 \mathrm{~m}$ high by $1.2 \mathrm{~m}$ wide with element size $5 \mathrm{~mm} \times 5 \mathrm{~mm}$ in within

11 the window plane. For the $7.52 \mathrm{~mm}$ laminated pane, it consists of 2 layers of $3 \mathrm{~mm}$ thick annealed glass and one layer of $1.52 \mathrm{~mm}$ PVB interlayer. Each layer has two elements in the thickness direction (Figure 9b). For the doubly laminated pane described above in test 7 , each of the three $6 \mathrm{~mm}$ thick glass plies and the two $1.52 \mathrm{~mm}$ PVB interlayers are also meshed with two elements along the thickness direction. The window frame comprises a $20 \mathrm{~mm}$ thick inner and a $10 \mathrm{~mm}$ thick outer steel strip. The frame is also meshed with $5 \mathrm{~mm} \times 5 \mathrm{~mm} \times 5 \mathrm{~mm}$ solid elements. Full integration is adopted in the numerical simulation. Blast load is applied on the surface of the outer glass layer (as demonstrated in Figure 9b). Considering symmetry, only one quarter of the window specimen is included in the model. Erosion is introduced to model glass crack and interlayer rupture. The mass of the deleted elements is retained so as to maintain mass conservation. Figure $9 a$ and $b$ illustrate the numerical model generated for the laminated glass window in the current field blast tests. Figure 9c-f show the numerical models built for laminated glass with bolt anchor and bar anchor which will be described in detail in the following sections.

\subsubsection{Convergence study}

A mesh size sensitivity test is performed to determine the optimized element size. The number of element in the window thickness direction is kept the same to ensure the stress variation across the pane depth is captured. Five different planer mesh 
1 sizes, namely $50 \mathrm{~mm}, 20 \mathrm{~mm}, 10 \mathrm{~mm}, 5 \mathrm{~mm}$, and $2 \mathrm{~mm}$ are used to model the

2 laminated glass panel in convergence test. The maximum pane central deflection is

3 chosen to check the simulation convergence. As shown in Figure 10, when simulating

4 the $7.52 \mathrm{~mm}$ laminated pane in test 3 , the resulted maximum deflection converges

5 with $5 \mathrm{~mm}$ mesh. Further reducing the mesh size to $2 \mathrm{~mm}$ does not lead to any

6 significant variation on the numerical results, but it leads to substantial increase in

7 the computational time. Therefore, the mesh size is chosen to be $5 \mathrm{~mm}$.

$8 \quad 3.1 .3 \quad$ Material model

9 Glass

10 Glass is a complex material. The failure of glass is brittle. Compressive test on 11 annealed glass material found its ultimate compressive strength could be over 1GPa 12 [15]. The theoretical tensile strength of glass crystal can even reach 21GPa [16]. 13 However, because of existing flaws on its surface during manufacture and service, 14 annealed glass used for architectural windows normally fails between 8MPa to $1545 \mathrm{MPa}$ [8]. A Weibull distribution is often introduced by some researchers to describe the tensile strength of glass for design purposes. When dealing with glass under ballistic impact or under blast loading, it is normally treated as a brittle material with a damage model to describe the strength deduction due to damage $[15,17,18]$.

Recent studies on annealed glass material properties have found glass to be a strain-rate sensitive material $[19,20]$. The dynamic increment factors (DIF) have been concluded. As shown in Figure 11, both the compressive and tensile strengths of architectural annealed glass will be amplified when it deforms at high strain rates. The strength increment at high strain rate could be caused by either the true material strength increment or the structural confinement effect in high-speed impact tests. Brown attributed the increase in glass strength to the assumption that

27 flaws and cracks take time to extend to form rupture [21]. More thorough study is needed to better understand dynamic glass material properties.

Based on previous studies on dynamic material properties of annealed glass material, the material constants of the popularly used Johnson Holmquist Ceramic 
$1(\mathrm{JH} 2)$ material model are recently derived for architectural annealed glass. $\mathrm{JH} 2$ model

2 is a well-defined material model for ceramic and glass materials. It includes a

3 strength model, a damage model, strain-rate effect, and equation of state (EOS). The

4 strength of material is depicted by the following equation

$$
\sigma^{*}=\sigma_{i}^{*}-D\left(\sigma_{i}^{*}-\sigma_{f}^{*}\right)
$$

5 where $\sigma_{i}^{*}$ is the normalized intact strength, $\sigma_{\mathrm{f}}^{*}$ is the normalized material strength

6 at fracture, and $\mathrm{D}$ is the damage scalar $(0 \leq \mathrm{D} \leq 1)$.

7 The normalized intact strength and material strength at fracture with strain-rate

8 effect are given by

$$
\sigma_{i}^{*}=A\left(P^{*}+T^{*}\right)^{N}\left(1+C \ln \dot{\varepsilon}^{*}\right)
$$

9 and

$$
\sigma_{\mathrm{f}}^{*}=\mathrm{B}\left(\mathrm{P}^{*}\right)^{\mathrm{M}}\left(1+\mathrm{Cln} \dot{\varepsilon}^{*}\right)
$$

10 where $A, B, C, M, N$ and $T$ are material constants; $\mathrm{P}^{*}$ stands for the normalized 11 pressure $\left(\mathrm{P}^{*}=\mathrm{P} / \mathrm{P}_{\mathrm{HEL}}\right)$, where $\mathrm{P}$ is the actual pressure and $\mathrm{P}_{\mathrm{HEL}}$ is the pressure at HEL. 12 Similarly, $T^{*}$ is the normalized maximum tensile hydrostatic pressure $\left(T^{*}=T / P_{\text {HEL }}\right) . \dot{\varepsilon}^{*}$ 13 is the actual strain rate over the reference strain rate $\left(\dot{\varepsilon}^{*}=\dot{\varepsilon} / \dot{\varepsilon}_{0}\right.$, where $\left.\dot{\varepsilon}_{0}=1.0 \mathrm{~s}^{-1}\right)$.

14 The damage owing to glass fracture in the $\mathrm{JH} 2$ model is defined by

$$
\mathrm{D}=\sum \Delta \varepsilon_{\mathrm{P}} / \varepsilon_{\mathrm{p}}^{\mathrm{f}}
$$

15 where $\Delta \varepsilon_{\mathrm{P}}$ is the plastic strain during a cycle of integration, and $\varepsilon_{\mathrm{p}}{ }^{\mathrm{f}}$ is the plastic

16 strain to fracture under constant pressure $P$,

$$
\varepsilon_{\mathrm{p}}^{\mathrm{f}}=\mathrm{D}_{1}\left(\mathrm{P}^{*}+\mathrm{T}^{*}\right)^{\mathrm{D}_{2}}
$$

17 where $D_{1}$ and $D_{2}$ are material constants.

18 The equation of state for glass under compression is expressed as

$$
P=K_{1} \mu+K_{2} \mu^{2}+K_{3} \mu^{3}+\Delta P
$$


1 where $K_{1}, K_{2}, K_{3}$ are constants, and $K_{1}$ is the material bulk modulus. $\mu=\rho / \rho_{0}-1$, in

2 which $\rho$ is the current density and $\rho_{0}$ is the initial density.

3 The original JH2 model for float glass was developed to simulate its ballistic

4 performance based on limited experimental testing data. Based on static and

5 dynamic laboratory test results on architectural annealed glass, together with

6 previous experimental investigations on window glass, Zhang and Hao derived

7 material constants for the modified JH2 model $[17,18]$. Through comparisons with

8 experimental results, the $\mathrm{JH} 2$ model with newly derived material constants has been

9 proved to give reliable results in simulation of annealed glass window responses

10 under shock and impact loads. In the current numerical model, this model is adopted

11 for annealed glass material.

$12 \quad P V B$

13 Experimental investigations on PVB material show that PVB exhibits viscoelastic 14 property under quasi-static loading. As a polymer material, PVB fails at strain over $15200 \%$. The Mooney-Rivlin model is generally chosen to model the hyperelastic behavior of PVB when it is loaded slowly. However, dynamic tensile tests performed on PVB by various researchers $[10,22-24]$ indicated that as loading rate increases the behavior of PVB gradually transforms from viscoelastic into elasto-plastic like with an initial rise in stress and then a reduced modulus before failure. At high strain rate, the behavior of PVB could even be brittle. The authors have recently conducted some dynamic direct tensile tests on PVB material as well [25]. It was found that

22 when the strain rate is above $2 s^{-1}$, PVB basically behaves as an elasto-plastic material. 23 Under blast loading, the strain rate that a material experiences is generally above $2410 \mathrm{~s}^{-1}$. A strain rate dependent elasto-plastic material model is therefore chosen for 25 PVB. 
1 The PVB initial Young's modulus, yield stress, and ultimate failure stress at various strain rates reported by previous researchers are collected and fitted into

3 equations with respect to strain rates for these quantities as:

$$
\begin{aligned}
E_{\text {initial }} & =30.591\left(\frac{\dot{\varepsilon}}{\dot{\varepsilon}_{0}}\right)^{0.271} \mathrm{MPa} \\
\sigma_{\text {yield }} & =2.167\left(\frac{\dot{\varepsilon}}{\dot{\varepsilon}_{0}}\right)^{0.399} \mathrm{MPa} \\
\sigma_{\text {failure }} & =27.689\left(\frac{\dot{\varepsilon}}{\dot{\varepsilon}_{0}}\right)^{0.040} \mathrm{MPa}
\end{aligned}
$$

4 where $\dot{\varepsilon}$ is the strain rate that material experienced, and $\dot{\varepsilon}_{0}$ is a reference strain rate 5 of $1 \mathrm{~s}^{-1}$. The density of PVB is $1100 \mathrm{~kg} / \mathrm{m}^{3}$ and the Poisson's ratio is 0.495 . The $2^{\text {nd }}$ 6 modulus measured in the experiments is averaged, and $11 \mathrm{MPa}$ is taken in this study.

7 The fitted stress-strain relations are programmed and implemented into LS-DYNA 8 code to conduct the numerical simulations. Detailed description of the strain-rate9 dependent elastoplastic model for PVB material is provided in reference [26]. It is 10 worth noting that dynamic tensile tests show that after PVB specimen fractures, 11 most of its deformation gradually recovered indicating viscoelastic nature of PVB 12 material [25]. Since there is not yet testing data on the dynamic unloading behaviour 13 of PVB, it is difficult to exactly model its unloading response of PVB, and in general 14 assumptions and simplifications have to be made. Some previous articles [27-29] 15 have discussed the basis and accuracies of using an elasto-plastic model for plastic 16 materials similar to PVB. In this study, much attention has been paid to the response 17 of PVB during numerical verification. Through comparing with field testing results, 18 the numerical model with the adopted material model for PVB was found to be 19 capable to properly simulate the response of the laminated glass windows. 20 Nevertheless, once testing data describing the unloading behaviour of PVB material 21 is available, a more accurate material model for PVB is to be generated.

A linear elastic material model is used for the steel frame with steel density $7800 \mathrm{~kg} / \mathrm{m}^{3}$, Young's modulus 200GPa, and Poisson's ratio 0.3. The choice of a simple material model rather than a more complicated model for the window frame is because the designed window frame in the field test is thick enough, and no material 
1 yielding or plastic deformation was observed on the steel frame. A simple elastic material model could help to improve computational efficiency without sacrificing precision.

4 For the fixture bar and bolt in the interlayer anchorage systems, to model the possibility of steel yielding, PIECEWISE LINEAR PLASTICITY material model (MAT024) in LS-DYNA is used. The yield's stress and tangent modulus are set to $270 \mathrm{MPa}$ and 470MPa respectively.

\subsubsection{Contact algorithm}

To define the interactions between different components of laminated glass window, the contact options in LS-DYNA is utilized. Different types of contact are defined based on the specific material and connections that are described below.

The current work focuses on studying the influence of window frame to the overall response of the glass windows. As described above in the field test, the laminated glass panes are proposed to be clamped by two pieces of steel frames, which are bolted together firmly. The friction on the contact surfaces between glass and steel prevents glass pane slipping out of the frame. The contact option AUTOMATIC SURFACE TO SURFACE in LS-DYNA is used with static friction coefficient of 0.7 and dynamic friction coefficient of 0.5 to simulate the interaction between glass and steel frame. The inner window frame is initially fixed. A clamping pressure of $10 \mathrm{MPa}$ is applied to the outer window frame to model the bolt clamping effect.

Observation in field blast tests on laminated glass found that delamination hardly occur between fractured glass and PVB interlayer. Glass debonding from PVB layer is therefore not modelled. The contacting nodes between PVB and glass are merged together. This simplification helps to improve computation efficiency.

The interactions between PVB interlayer and fixtures bars, as well as PVB with fixture bolts are modeled with three dimension contact, AUTOMATIC SURFACE TO

27 SURFACE option, in the numerical simulation. Considering the relatively low modulus of PVB material as compared to steel, soft constraint formulation instead of the default penalty formulation is used in LS-DYNA. 
To verify the accuracy and reliability of the numerical model, two window tests are numerically simulated. The laminated pane 1-1-1 with $50 \mathrm{~mm}$ bite depth

4 subjected to $10 \mathrm{~kg}$ TNT at $10 \mathrm{~m}$ stand-off distance without boundary failure is 5 simulated first. Then the numerical simulation is extended to model the laminated pane with total failure along window boundary, i.e., the laminated pane tested by Hooper et al. [9], which was pulled out of the frame completely and propelled into the testing cell, is modelled.

\subsubsection{Without boundary failure}

In test 1 , the $7.52 \mathrm{~mm}$ laminated glass window with $50 \mathrm{~mm}$ bite was subjected to the blast loads from $10 \mathrm{~kg}$ TNT detonated at $10 \mathrm{~m}$ stand-off distance. The recorded reflected pressure in the field test is simplified as shown in Figure 12 and applied to the outer glass ply.

Figure 13 shows the comparison of the simulated and field tested laminated glass windows. As shown, the numerical model manages to simulate the overall response of the laminated pane under the field blast load. The glass plies are both extensively shattered with the most severe damage at the corners. The central region of the laminated pane is relatively intact. There is no sign of the cracked laminated pane being pulled out of its boundary. Figure 12 compares the deflection histories at the pane centrals. The predicated central displacement shows good agreement with the measured data in the field test. A maximum deflection of $268 \mathrm{~mm}$ is predicated in comparison with $275 \mathrm{~mm}$ in the field test. The error is less than $3 \%$, indicating good numerical predictions. The numerical model slightly underestimates the peak deflection of the laminated pane, due to a number of uncertainties, especially the errors in material models.

\subsubsection{With boundary failure}

Hooper et al. tested a $7.52 \mathrm{~mm}$ thick laminated glass window of dimension $1.5 \mathrm{~m}$ by $1.2 \mathrm{~m}$ with $25 \mathrm{~mm}$ bite depth [9]. Under the blast loading from $30 \mathrm{~kg}$ TNT equivalent charge detonated at $14 \mathrm{~m}$ away, the laminated glass pane was totally 
1 pulled out of the window frame and was propelled into the testing cell. To further calibrate the numerical model, this test is also simulated in the study. The measured reflected pressure reported in [9] is fitted and applied to the laminated glass as shown in Figure 14.

Figure 15 depicts the failure state of the prediction using the numerical model and that observed in the field blast test. As can be seen, the numerical model predicts a very similar failure mode of the laminated glass pane. In the numerical model the glass around the centre of the pane is relatively intact, while the damage of the pane in the Hooper's test is not visible due to the stochastic speckle pattern applied on the window surface for digital image correlation. The cracked laminated panes are both pulled out of the window frame along four sides, leaving only pane corners held by the frames at the instant shown in Figure 15. Under the blast loading, the cracked glass pane works as a whole without interlayer rupture and flies into the room. The pane central deflection histories shown in Figure 14 provides further evidence that the numerical model agrees well with the measured data in the field test. The laminated glass pane deforms under the effect of the blast pressure. In the field test at about $11 \mathrm{~ms}$, the shattered laminated pane is completely pulled out of the window frame with a maximum central deflection of $265 \mathrm{~mm}$. In comparison, the laminated pane in the numerical model is totally pulled out of the window frame at around $12 \mathrm{~ms}$ with a central deflection of $275 \mathrm{~mm}$. The laminated glass pane without any constrains from its frame continued to travel into the room.

Through the above comparisons, it can be concluded that the numerical model gives reasonable predictions of the laminated glass window response to blast loads. The constraining effect of window frame can be properly simulated by the numerical model.

\subsection{Numerical results and analysis}

\subsubsection{Frame bite depth}

The effect of bite depth on the responses of laminated glass windows is studied by numerically simulating $7.52 \mathrm{~mm}$ thick $1.5 \mathrm{~m} \times 1.2 \mathrm{~m}$ laminated panes with four 
1 dimension ratios of $0.008,0.017,0.042$ and 0.058 , respectively. Three load cases are considered in the analysis, i.e., a low level blast with $20 \mathrm{~kg}$ TNT explosive detonated

$330 \mathrm{~m}$ away to generate Level $\mathrm{C}$ blast loading $\left(\mathrm{Pr}^{+}=27 \mathrm{kPa}\right.$ lasting about $\left.7 \mathrm{~ms}\right)$ following 4 GSA standard [30]. The magnitude of blast pressure is estimated following UFC 3340-02 [31]. An intermediate high level blast with reflected pressure recorded in test 1 in the field test above, and a high level blast pressure as recorded in test 2 . The reflected pressures applied are presented in the following with respective pane deflection histories, where the negative phases are also included.

When subjected to the low level blast load, the simulations indicate that all the laminated panes survive the blast load without joint failure as shown in Figure 16. Despite glass cracking occurs on all laminated panes, interlayer ruptures are not found. The pane central displacement histories in Figure 17 show that all the four laminated panes respond similarly to the blast load. The panes with $10 \mathrm{~mm}$ and $20 \mathrm{~mm}$ embedment respond marginally slower than the other two panes with deep bites. This is probably because the shallow bite depth resulted in slightly flexible window system, which as a result responds a bit slower. Higher deflections were found on the panes when they rebounded, which were due to the effect of negative pressure.

As shown in Figure 18, under the intermediate level blast load, glass plies of all panes experience severe damage, but the laminate panes with different bite depths respond very differently. With $10 \mathrm{~mm}$ and $20 \mathrm{~mm}$ bite depths, the laminated panes are easily pulled out of their window frames and pushed into the room. When increasing the bite depth to $50 \mathrm{~mm}$ and $70 \mathrm{~mm}$, the laminated panes are restrained between the steel frames. Figure 19 shows the time histories of displacement at pane centrals. As shown, the laminated pane with only $10 \mathrm{~mm}$ embedment is quickly pulled out of its frame and propelled under the blast load. With slightly larger embedment $(20 \mathrm{~mm})$, the pane receives more restraint from its frame, and responds slightly slower, but failure along window boundary still occurs. For the two laminated panes with larger bite depths $(50 \mathrm{~mm}$ and $70 \mathrm{~mm})$, they survive the blast load without being pulled out of their frames. As can be seen from Figure 19, the pane with $50 \mathrm{~mm}$ embedment reaches a bit higher maximum deflection $(268 \mathrm{~mm})$ as compared with 
1 the other pane with $70 \mathrm{~mm}$ bite depth $(251 \mathrm{~mm})$. This is because of insufficient

2 friction restraint from the $50 \mathrm{~mm}$ bite frame, and relative in-plane sliding still

3 happens. The $50 \mathrm{~mm}$ deep bite manages to withstand the pull forces.

4 As shown in Figure 20, under the high blast loading the glass plies of all the 5 laminated panes are shattered. The two laminated panes with shallow bites $(10 \mathrm{~mm}$ 6 and $20 \mathrm{~mm}$ ) fail by being pulled out from their frames perimetrally. When increasing 7 bite depth to $50 \mathrm{~mm}$, the pane survives the positive phase blast loading and reaches 8 a maximum deflection of $316 \mathrm{~mm}$ without any joint failure (Figure 21). The pane 9 rebounds, together with the action of negative blast pressure a higher central 10 deflection is resulted. When the pane central deflection reaches $354 \mathrm{~mm}$, the restraint of the $50 \mathrm{~mm}$ deep bite is no longer able to hold the laminated pane from the suction of negative pressure. Pulling-out failure happens to the laminated pane embedded in $50 \mathrm{~mm}$ bite frame during rebound at about $40 \mathrm{~ms}$. It is worth noting that the PVB interlayer on the laminated pane with $50 \mathrm{~mm}$ bite experiences significant deformation, but no interlayer rupture is found to the PVB membrane which is because the relative in-plane sliding occurred between the pane and frame when the pane is deflecting into the room. The relative slide of the pane reduces the deformation of the PVB interlayer and reliefs its rupture potential. When increasing the bite depth to $70 \mathrm{~mm}$, a more robust fully fixed support is created for the laminated glass window. The steel frame with deep bite holds the laminated pane firmly when it is under the action of the blast pressure. No joint failure occurs to the laminated pane. However, as shown in Figure 20 the interlayer of the laminated pane is torn when the pane is deflecting inward. This is because of the large magnitude blast pressure resulting significant shear and flexural deformation to the laminated pane. The deep-bite frame restrains the pane firmly from any in-plane sliding. Without any relief from sliding, the PVB interlayer ruptures when its principal strain reaches the ultimate capacity.

Through the above analysis, it can be found that providing sufficient bite depth is an effective way to mitigate joint failure of laminated windows, reduce the risk of 
1 boundary is too rigid, as in the case with $70 \mathrm{~mm}$ bite, it might make the glass pane more vulnerable to blast load.

\subsubsection{Interlayer anchorage}

Trawinski et al. [13] introduced two types of anchorage measures to reduce the risk of laminated glass pane being pulled out of its frame. The two anchorage measures are (1) using fixture bars along two sides of the window frame to hold the extended PVB interlayer and (2) using fixtures bolts to fix extended PVB strips to the window frame. The details of these two measures are illustrated in Figure $9 \mathrm{c}$ to $\mathrm{f}$. $1.5 \mathrm{~m} \times 1.2 \mathrm{~m}$ doubly laminated glass pane with three glass plies and two PVB interlayers are modelled in the study. $50 \mathrm{~mm}$ wide steel frame is assumed to be installed to clamp the pane in position. $10 \mathrm{~mm}$ diameter high strength steel rods are positioned along the two vertical sides of the window frame as the fixture bars, which are anchored at their both ends with full restraint into the frame. The extended PVB interlayer wraps around the fixture bar (Figure 9e and f). When the PVB interlayer is under tension as the laminated pane deforms, the two steel bars will hold the interlayer to prevent it from sliding. For the laminated pane with fixture bolt retrofit, an extra 100mm PVB strips are extended from the laminated pane. 20 pieces of M10 high strength steel bolts are fixed perimetrally around the window frame at $200 \mathrm{~mm}$ spacing. These fixture bolts go through the pre-drilled holes on the extended PVB strips, and are fully fixed onto the wall (Figure $9 \mathrm{c}$ and d). Similar to the fixture bars, these bolts will hold the PVB interlayer when the laminated pane is under blast loading. To check the effectiveness of these two interlayer anchorage measures, the laminated glass pane without any interlayer anchorage retrofit is also modeled to provide reference. The responses of laminated glass windows are simulated with four different levels of blast loadings, i.e. a small scale blast with $20 \mathrm{~kg}$ TNT detonated at 30m distance to generate blast load following GSA standard Level C, an intermediate level blast load as in the current field blast Test 1 with 10kg TNT detonated at $10 \mathrm{~m}$ distance, a large-scale blast load as in Test 7 with $20 \mathrm{~kg}$ TNT detonated at $7.2 \mathrm{~m}$ distance, and an extra-large-scale blast load with $90 \mathrm{~kg}$ TNT detonated at $10 \mathrm{~m}$ stand-off distance, respectively. The magnitude of blast loads are 
1 estimated following UFC 3-340-02 [31]. The reflected pressure time histories are shown in Figure 22, where the negative phases are also included.

Figure 23 depicts the ultimate failure states of laminated glass windows with fixture bar and fixture bolt, and without any interlayer anchorage retrofit but $50 \mathrm{~mm}$ bite only. As shown, under the minimum level of blast loading (small scale), none of the laminated panes experiences any noticeable damage which is due to the large flexural strength of the $21.04 \mathrm{~mm}$ (6mm glass, $1.52 \mathrm{~mm}$ PVB, $6 \mathrm{~mm}$ glass, $1.52 \mathrm{~mm}$ PVB, and $6 \mathrm{~mm}$ glass) doubly laminated pane, as well as the increased inertial resistance owing to the large mass, as compared to the $7.52 \mathrm{~mm}$ laminated glass window discussed above. Figure 22a shows the central displacement histories. As shown, barely any difference can be found on the central displacement histories among the three laminated panes. When the laminated glass windows are under intermediatescale blast loading, glass cracks can be observed on the laminated panes (Figure 23). The central displacement histories indicate a maximum deflection (about $42 \mathrm{~mm}$ ) is reached on the laminated pane without anchorage measure. Due to the extra restraint effects from the fixture bars and fixture bolts, lower central deflections are and $35 \mathrm{~mm}$ respectively). Fixture bolts appears to provide slightly better resistance perimetrally to the cracked laminated pane with a bit smaller central deflection resulted. Under the large-scale blast loading, the laminated pane without any interlayer anchorage is pulled out of its frame along the two vertical boundaries. A maximum central deflection of about $245 \mathrm{~mm}$ is predicted. But with the friction resistance from the top and bottom boundaries and the four corners, the cracked pane finally comes to a rest within the window frame. The negative blast pressure appears to have insignificant influence on the doubly laminated panes that it does not suck out the glass pane. This is probably because of the heavier mass of the doubly laminated panes comparing with the $7.52 \mathrm{~mm}$ singly laminated panes. In comparison, the fixture bar is quite effective that they successfully hold the laminated pane along its two vertical boundaries from being pulled out of the window frame. The maximum pane central deflection is about $195 \mathrm{~mm}$. The fixture bolts provides similar anchorage effect to the sliding interlayer. As a result of bolt 
1 anchor, a maximum central deflection of about $193 \mathrm{~mm}$ is predicted, which is $21 \%$

2 lower than the case without boundary anchorage. Comparing the effectiveness of

3 fixture bar and fixture bolt, it seems that the bolt anchors yield slightly better

4 performance of laminated glass windows under the current blast loading. This is

5 because the bolt anchor provides additional resistance to stop the interlayer from

6 sliding perimetrally. In comparison, the fixture bar can only hold the interlayer along

7 its two sides. As shown in Figure 23, because the bars are fixed into the frame on

8 their two ends, the $1.5 \mathrm{~m}$ long $10 \mathrm{~mm}$ diameter steel bars yield under the substantial

9 pulling forces from the PVB interlayer when the laminated glass pane is under large

10 blast loads. The deformation of the fixture bars curves into the window which makes

11 the laminated pane slide inward and consequentially leads to slightly higher central

12 deflection. Close observation on the extended PVB strips at the fixture bolts; it can

13 also found that interlayer tearing could be a major potential problem when the

14 laminated pane is under substantial tensile forces from the blast load. Under the

15 extra-large-scale blast loading from $90 \mathrm{~kg}$ TNT detonated at $10 \mathrm{~m}$ stand-off distance,

16 the laminated pane without interlayer anchorage is directly pushed into the testing

17 room with laminated pane being widely pulled out of the window frame around the

18 four sides. The laminated pane with fixture bars does not survive the substantial

19 blast load either. The fixture bars pull the laminated pane back from sliding initially.

20 However, under the large blast pressure, the laminated pane experiences substantial

21 deformation, which pulls the fixture bars and causes significant bending and

22 curvature on the steel bars. Rupture eventually occurs on the PVB interlayer near

23 and in contact with the anchor bars. After PVB rupture along the anchor bars, the

24 laminated pane is pulled out of the window frame from the top and bottom sides

25 and then pushed into the room. Similar response is observed on the laminated pane

26 with fixture bolts. As shown in Figure 23, as the laminated pane deforms, the

27 extended PVB strips are torn through the bolt holes. From the deflection histories

28 shown in Figure 22d, it can be observed that the central deflections of all the three

29 laminated panes kept increasing, indicating they are flying into the room. The fixture

30 bar and fixture bolts delay marginally the failure along the window frame. 
1 Through the above analysis, it can be found that anchor bars and bolt can help to mitigate the potential of joint failure along laminated glass pane boundaries. Their

3 effectiveness is quite obvious when the laminated glass windows are subjected to certain levels of blast loadings. When the window is under low level blast loading, the laminated pane itself and the clamping window frame could provide sufficient resistance to stop pane from being pulled out. The effect of interlayer anchor is not apparent. When the laminated glass window is subjected to large blast loading, PVB interlayer rupture at the locations in contact with the anchor bars and PVB interlayer tearing at the fixture bolts might occur, resulting in the failure of the anchoring system.

\section{Sliding boundary}

Zhang et al. [6] studied the effect of releasing boundary restraint on improving the anti-blast performance of laminated glass windows. Comparing with the fully fixed boundary condition, the capacity of laminated glass panes were found to increase when using pinned boundary which allowed the rotation of the laminated pane along its boundary. It was found that using a flexible window boundary might mitigate the damage of the laminated pane under blast pressure. Following this idea, a sliding boundary is proposed, which allows the laminated pane to slide freely in the direction of blast pressure. The laminated pane slides backward to mitigate the blast load when the air blast wave pushes it inward. A doubly laminated pane with three glass plies laminated by two PVB interlayers with sliding boundary is tested in this study to examine the effectiveness of using this flexible boundary to mitigate window glass damage. To minimize the possibility of the glass pane failure or rupture immediately after the application of blast loading, strong doubly laminated glass panes as described above were tested to observe the influences of sliding boundary.

In the field blast test 7 described above, two doubly laminated glass windows (as shown in Figure $2 \mathrm{~b}$ ), one with fixed boundary and another one with the proposed sliding boundary, were tested. The pressure transducer recorded a peak reflected pressure of $514 \mathrm{kPa}$ lasting about $3 \mathrm{~ms}$. Figure 24 shows the snapshots of high-speed camera images for the laminated pane with sliding boundary. It can be observed that 
1 after the blast wave arrived at the window $8 \mathrm{~ms}$ after detonation, the glass plies cracked immediately. The entire pane also began to slide inward under the action of

3 the blast wave. At around $20 \mathrm{~ms}$, the laminated pane touches the inner window

4 frame after sliding $50 \mathrm{~mm}$ inward. The maximum deformation occurred at the pane central at about $40 \mathrm{~ms}$ after which the pane starts to rebound.

Figure 25 shows the failure patterns of the two laminated panes with fully fixed and with sliding boundaries in test 7. As shown in Figure 25a, the laminated pane with sliding boundary suffers severe damage to its glass plies by the substantial blast load. However, only small joint failure could be observed along its boundary, and no PVB rupture was observed. The action of blast pressure was vastly mitigated as the laminated pane slid backwards. In comparison, the laminated pane which was fully clamped between the steel window frames suffered significant joint failure especially along its two vertical boundaries (Figure 25b), as well as PVB rupture. The image of pane failure indicates the fully fixed glass pane with $50 \mathrm{~mm}$ bite depth to the laminated pane is insufficient to prevent pulling-out failure. Comparing the damage level of the two identical glass panes with different boundary conditions clearly demonstrates that using flexible boundary can mitigate damages of laminate glass windows under blast loadings.

No LVDT was installed in this test to prevent damaging them by the failed glass window flying into the testing cell because of the expected large blast loads. Instead the high-speed camera images are post-processed using a Matlab tracking algorithm with the aid of the tracking dot matrix on the glass pane to derive the pane displacement histories. Figure $25 \mathrm{c}$ shows the predicted pane failure. As shown, the numerical model manages to replicate the pulling-out failure along two boundaries. From the numerical model, pane displacements at various locations can be easily tracked. The displacement histories at the centres of the two tested panes obtained by both numerical simulation and high-speed camera images in the field test are presented in Figure 26. As can be seen, the deflection at pane centre for the pane with fixed boundary increased immediately under the blast load. The central deflection rises quickly to a maximum of about $247 \mathrm{~mm}$ and then recovers as pane rebounded. The deflection near the window boundary increases simultaneously with 
1 pane central. But because of the restraint from window frame, low magnitude of deflection is resulted. High-speed camera images found the displacement at pane centre of the laminated pane with sliding boundary increased slower at the beginning. The displacement is mainly associated with the sliding of the entire pane. Similar displacement was recorded at the pane boundary until it approximated $50 \mathrm{~mm}$, which is the design sliding distance for the laminated pane. The displacement at pane centre is slightly larger than that at the boundary because of pane deformation under the blast wave effect. After this instance when the laminated pane touches the inner window frame, the displacement near the boundary begins to increase slowly similar to the case with fixed boundary. The central displacement starts to rise quickly until a maximum deflection is reached (about $251 \mathrm{~mm}$ ) and then reduces as pane rebounded. Comparing the central displacement histories of the laminated panes with sliding and fixed boundaries, it can be found the sliding pane responds slower due to its flexibility. If the sliding distance is deducted from the deflection at the central, a much smaller central deflection is resulted (about $201 \mathrm{~mm}$ ). It indicates $19 \%$ less net maximum central deflection is achieved with the sliding boundary comparing with the fully fixed boundary, which consequentially reduces the rupture possibility of the laminated pane. As shown in Figure 25a and b, no PVB tearing was found on the laminated pane with sliding boundary. However, some insignificant interlayer rupture was found after closely examining the laminated pane clamped with fully fixed boundary.

Through the above comparisons, it can be found that the sliding boundary can help to improve the blast resistance capacity of the laminated glass windows. Lower net central deflection can be achieved by the sliding boundary comparing with the traditional fully fixed boundary. The field blasting test also shows that the sliding boundary reduces the potential of joint failure.

\section{Conclusion}

28 The responses of laminated glass windows were examined through full-scale field 29 blast tests and numerical simulations. The failure pattern was found to be primarily 30 joint failure, where the cracked laminated panes were pulled out of the steel frames. 
1 Previous field blast test results were collected together with the current testing data

2 to analyze the formation and influencing factors of joint failure. Numerical model of

3 laminated glass windows was built and calibrated with testing data, and then used to

4 study the influence of bite depth to joint failure. Numerical simulations were further

5 carried out to investigate the effectiveness of two types of interlayer anchorage

6 systems, namely fixture bar and fixture bolt. The efficiencies of the two anchorage

7 systems were studied. It was found for intermediate to large scale blast loadings,

8 interlayer anchorage with fixture bar and fixture bolts can effectively mitigate the

9 laminated pane joint failure. However, increasing the boundary anchorage increases

10 the PVB rupture potential. Based on previous founding on boundary effect to the

11 performance of laminated glass windows, a new sliding boundary was introduced

12 and tested experimentally. The advantages and disadvantages of the sliding

13 boundary was discussed and checked through comparison with fully fixed boundary.

14 It was found the new sliding boundary can effectively reduce the laminated pane

15 response against blast loading, and also reduce the joint failure possibility.

\section{Acknowledgement}

The authors would like to thank Australian Research Council for financial support. Support from the State Key Laboratory of Science and Technology of Beijing Institute of Technology with its collaborative research scheme under project number KFJJ11-3 is also acknowledged. The first author would also like to thank the University of Western Australia for providing Ad Hoc scholarship.

\section{Reference}

[1] H.S. Norville, N. Harvill, E.J. Conrath, S. Shariat, S. Mallonee, Glass-Related Injuries in Oklahoma City Bombing, Journal of Performance of Constructed Facilities, 13 (1999) 50.

[2] J.L. Smith, Anti-terrorism: Criteria, tools \& technology, Applied Research Associates, Inc, (2003) 4.

[3] L.H. Lin, E. Hinman, H.F. Stone, A.M. Roberts, Survey of Window Retrofit Solutions for Blast Mitigation, Journal of Performance of Constructed Facilities, 18 (2004) 8694.

[4] X. Zhang, H. Hao, Z. Wang, Experimental Investigation on Monolithic Tempered Glass Windows Responses to Blast Loads, International Journal of Protective Structures, Special Issue (2014). 
[5] X. Zhang, H. Hao, Z. Wang, Experimental investigation of monolithic tempered glass fragment characteristics subjected to blast loads, Engineering Structures, 75 (2014) 259-275.

[6] X. Zhang, H. Hao, G. Ma, Parametric study of laminated glass window response to blast loads, Engineering Structures, 56 (2013) 1707-1717.

[7] X. Zhang, H. Hao, G. Ma, Development of PI curve for laminate glass windows, in: Proceedings of Australasian Structural Engineering Conference 2012: The past, present and future of Structural Engineering, 2012.

[8] M. Larcher, G. Solomos, F. Casadei, N. Gebbeken, Experimental and numerical investigations of laminated glass subjected to blast loading, International Journal of Impact Engineering, 39 (2012) 42-50.

[9] P.A. Hooper, R.A.M. Sukhram, B.R.K. Blackman, J.P. Dear, On the blast resistance of laminated glass, International Journal of Solids and Structures, 49 (2012) 899-918. [10] C. Morison, The resistance of laminated glass to blast pressure loading and the coefficients for single degree of freedom analysis of laminated glass, PhD thesis, Cranfield University (2010).

[11] C. Kranzer, G. Gürke, C. Mayrhofer, Testing of Bomb Resistant Glazing SystemsExperimental Investigation of the Time Dependent Deflection of Blast Loaded 7.5 $\mathrm{mm}$ Laminated Glass, in: Proceedings of Proceedings of Glass Processing Days, Tampere, Finland, 2005.

[12] X. Zhang, H. Hao, Experimental Study of Laminated Glass Window Responses under Impulsive and Blast Loading, under review with International Journal of Impact Engineering, (2014).

[13] Elizabeth Trawinski, Jeff W. Fisher, R.J. Dinan, Full Scale Testing of Polymer Reinforced Blasting Resistant Windows, Air Force Research Laboratory, Florida, USA, 2004.

[14] M. Teich, N. Gebbeken, The Influence of the Underpressure Phase on the Dynamic Response of Structures Subjected to Blast Loads, International Journal of Protective Structures, 1 (2010) 219-234.

[15] T.J. Holmquist, G.R. Johnson, C. Lopatin, D. Grady, E.S. Hertel Jr, High strain rate properties and constitutive modeling of glass, in: Proceedings of 15th International Symposium on Ballistics Jerusalem, Israel, 1995.

[16] M. Overend, G. Parke, D. Buhagiar, Predicting Failure in Glass-A General Crack Growth Model, Journal of Structural Engineering, 133 (2007) 1146-1155.

[17] X. Zhang, H. Hao, Constitutive Model of Annealed Soda Lime Glass at High Strain Rates, 15th International Symposium on the Interaction of the Effects of Munitions with Structures, Federal Ministry of Defence, Germany, 2013, pp. No.160.

[18] X. Zhang, H. Hao, Dynamic Material Model of Annealed Soda-lime Glass under review with International Journal of Impact Engineering, (2014).

[19] M. Peroni, G. Solomos, V. Pizzinato, M. Larcher, Experimental Investigation of High Strain-Rate Behaviour of Glass, Applied Mechanics and Materials, 82 (2011) 6368.

[20] X. Zhang, H. Hao, G. Ma, Dynamic material model of annealed soda-lime glass, International Journal of Impact Engineering, 77 (2015) 108-119.

[21] W. Brown, A practicable formulation for the strength of glass and its special application to large plates, Tech. Rep. Publication No. NRC14372, National Research Council of Canada, Ottawa, 1974. 
1 [22] S. Bennison, J. Sloan, D. Kistunas, P. Buehler, T. Amos, C. Smith, Laminated glass

2 for blast mitigation: Role of interlayer properties, in: Proceedings of Glass Processing

3 Days, Tampere, Finland, 2005.

4 [23] R. Iwasaki, C. Sato, J. Latailladeand, P. Viot, Experimental study on the interface

5 fracture toughness of PVB (polyvinyl butyral)/glass at high strain rates, International

6 Journal of Crashworthiness, 12 (2007) 293-298.

7 [24] P. Hooper, B. Blackman, J. Dear, The mechanical behaviour of poly (vinyl butyral)

8 at different strain magnitudes and strain rates, Journal of Materials Science, 47 (2012)

9 3564-3576.

10 [25] X. Zhang, H. Hao, Y. Shi, J. Cui, The Mechanical Properties of Polyvinyl Butyral

11 (PVB) for Laminated Glass at High Strain Rates, manuscript under review with

12 Construction and Building Materials, (2015).

13 [26] X. Zhang, H. Hao, G. Ma, Laboratory test and numerical simulation of laminated

14 glass window vulnerability to debris impact, International Journal of Impact

15 Engineering, 55 (2013) 49-62.

16 [27] H. Lobo, Methodology for selection of material models for plastics impact

17 simulation, in: Proceedings of 10th International LS-Dyna User's Conference, 2006.

18 [28] H. Lobo, J. Hurtado, Characterization and modeling of nonlinear behavior of

19 plastics, in: Proceedings of ABAQUS User Conference, 2006.

20 [29] S. Kolling, A. Haufe, M. Feucht, P. Du Bois, SAMP-1: A Semi-Analytical Model for

21 the Simulation of Polymers, LS-DYNA Anwenderforum, (2005).

22 [30] General Services Administration, Standard Test Method for Glazing and Window

23 Systems Subject to Dynamic Overpressure Loadings, US, 2003.

24 [31] UFC 3-340-02, Structures to Resist the Effects of Accidental Explosions,

25 Department of Defense, United States of America, 2008. 
1 Table 1 Summary of blast test configurations

2 Table 2 Summary of recorded blast loads and estimations using K-B equation 3

4 


\begin{tabular}{|c|c|c|c|c|c|c|c|c|}
\hline $\begin{array}{l}\text { Test } \\
\text { No. }\end{array}$ & $\begin{array}{l}\text { Pane } \\
\text { No. }\end{array}$ & $\begin{array}{c}\text { Glass } \\
\text { thickness } \\
\text { (mm) }\end{array}$ & $\begin{array}{c}\text { PVB } \\
\text { thickness } \\
\text { (mm) }\end{array}$ & $\begin{array}{c}\text { Size } \\
(\mathrm{mm} \times \mathrm{mm})\end{array}$ & $\begin{array}{l}\text { Boundary } \\
\text { condition }\end{array}$ & $\begin{array}{c}\text { TNT } \\
\text { weight } \\
(\mathrm{kg})\end{array}$ & $\begin{array}{c}\text { Stand- } \\
\text { off } \\
\text { distance } \\
(\mathrm{m})\end{array}$ & Measurement \\
\hline 1 & $1-1-1$ & 3 & 1.52 & $1500 \times 1200$ & Fixed & 10 & 10 & $\begin{array}{l}\text { Pressure, } \\
\text { LVDT, HS }\end{array}$ \\
\hline 2 & $2-1-1$ & 3 & 2.28 & $1500 \times 1200$ & Fixed & 10 & 9 & $\begin{array}{l}\text { Pressure, } \\
\text { LVDT, HS }\end{array}$ \\
\hline 3 & $3-1-1$ & 3 & 1.52 & $1500 \times 1200$ & Fixed & 10 & 12.3 & $\begin{array}{l}\text { Pressure, } \\
\text { LVDT, HS }\end{array}$ \\
\hline 4 & $4-1-1$ & 3 & 1.52 & $1500 \times 1200$ & Fixed & 10 & 9.5 & Pressure, HS \\
\hline 6 & $6-1-1$ & 3 & 1.52 & $1500 \times 1200$ & Fixed & 20 & 11 & Pressure, HS \\
\hline 7 & $7-1-1$ & 6 & 1.52 & $1500 \times 1200$ & Fixed & 20 & 7.2 & Pressure \\
\hline 7 & $7-1-2$ & 6 & 1.52 & $1500 \times 1200$ & Sliding & 20 & 7.2 & Pressure, HS \\
\hline
\end{tabular}

Note: HS indicates high-speed image measurement available; LVDT indicates displacement measurement available; Pressure indicates reflected pressure measurement available.

Table 1 Summary of blast test configurations

2 


\begin{tabular}{|c|c|c|c|c|c|c|c|c|}
\hline \multirow{3}{*}{$\begin{array}{l}\text { Test } \\
\text { No. }\end{array}$} & \multirow{3}{*}{$\begin{array}{c}\text { TNT } \\
\text { Weight } \\
(\mathrm{kg})\end{array}$} & \multirow{3}{*}{$\begin{array}{l}\text { Stand- } \\
\text { off } \\
\text { distance } \\
\text { (m) }\end{array}$} & \multicolumn{4}{|c|}{ Field test } & \multirow{2}{*}{\multicolumn{2}{|c|}{$\begin{array}{c}\text { K-B } \\
\text { equation } \\
\text { Positive phase }\end{array}$}} \\
\hline & & & \multicolumn{2}{|c|}{ Positive phase } & \multicolumn{2}{|c|}{ Negative phase } & & \\
\hline & & & $\begin{array}{c}\mathrm{Pr} \\
(\mathrm{kPa})\end{array}$ & $\begin{array}{c}\text { Ir (kPa } \\
\mathrm{ms})\end{array}$ & $\begin{array}{c}\mathrm{Pr} \\
(\mathrm{kPa})\end{array}$ & $\begin{array}{c}\text { Ir (kPa } \\
\mathrm{ms})\end{array}$ & $\begin{array}{c}\mathrm{Pr} \\
(\mathrm{kPa})\end{array}$ & $\begin{array}{c}\operatorname{Ir}(\mathrm{kPa} \\
\mathrm{ms})\end{array}$ \\
\hline 1 & 10 & 10 & 121.1 & 395.0 & 28.4 & 319.7 & 117.2 & 293.86 \\
\hline 2 & 10 & 9 & 168.6 & 476.1 & 35.8 & 543.5 & 147.1 & 330.7 \\
\hline 3 & 10 & 12.3 & 82.2 & 413.3 & 17.5 & 261.7 & 78.1 & 233.7 \\
\hline 4 & 10 & 9.5 & 147.5 & 436.3 & 29.6 & 441.3 & 130.7 & 311.2 \\
\hline 6 & 20 & 11 & 172.1 & 534.5 & 31.8 & 548.5 & 157.5 & 431.2 \\
\hline 7 & 20 & 7.2 & 514.3 & 797.1 & 43.0 & 614.3 & 463.0 & 703.4 \\
\hline
\end{tabular}

2 
1 Figure 1 Testing site plan

2 Figure 2 Illustration of window specimens

3 Figure 3 Illustration of window frames

4 Figure 4 Recorded reflected pressure and pane central displacement histories

5 Figure 5 Snapshots of high-speed images for Pane 4-1-1 and 1-1-1

6 Figure 6 Failure patterns

7 Figure 7 Comparison of influence of bite depth

8 Figure 8 Maximum pane deflections versus bite depth at different reflected impulses

$9 \quad$ Figure 9 Laminated glass models

10 Figure 10 Mesh size sensitivity test

11 Figure 11 Johnson Holmquist Ceramic material model for annealed glass [18]

12 Figure 12 Pressure and central deflection time histories in field test and numerical

13 simulation for Pane 1-1-1

14 Figure 13 Comparison of failure patterns for pane 1-1-1

15 Figure 14 Pressure and central deflection histories in field test and numerical

16 simulation of Hooper et al.'s test [9]

17 Figure 15 Comparison of pane failure patterns of Hooper et al.'s test [9]

18 Figure 16 Failure patterns of windows with different bite depths under low level

19 blast loading

20 Figure 17 Blast load and pane central displacement histories of windows with

21 different bite depths under low level blast loading

22 Figure 18 Failure patterns of windows with different bite depths under intermediate

23 high level blast loading

24 Figure 19 Blast load and pane central displacement histories of windows with

25 different bite depths under intermediate high level blast loading

26 Figure 20 Failure patterns of windows with different bite depths under high blast

27 loading

28 Figure 21 Blast load and pane central displacement histories of windows with

29 different bite depths under high blast loading

30 Figure 22 Blast loads and pane central displacement histories for laminated glass

31 windows with different anchorage measures

32 Figure 23 Ultimate states of laminated glass windows with different retrofits 
1 Figure 24 Snapshots of high-speed images of the laminated pane with sliding

2 boundary

3 Figure 25 Failure patterns of the laminated panes in test 7

4 Figure 26 Comparison of displacement histories of test 7

5

6 


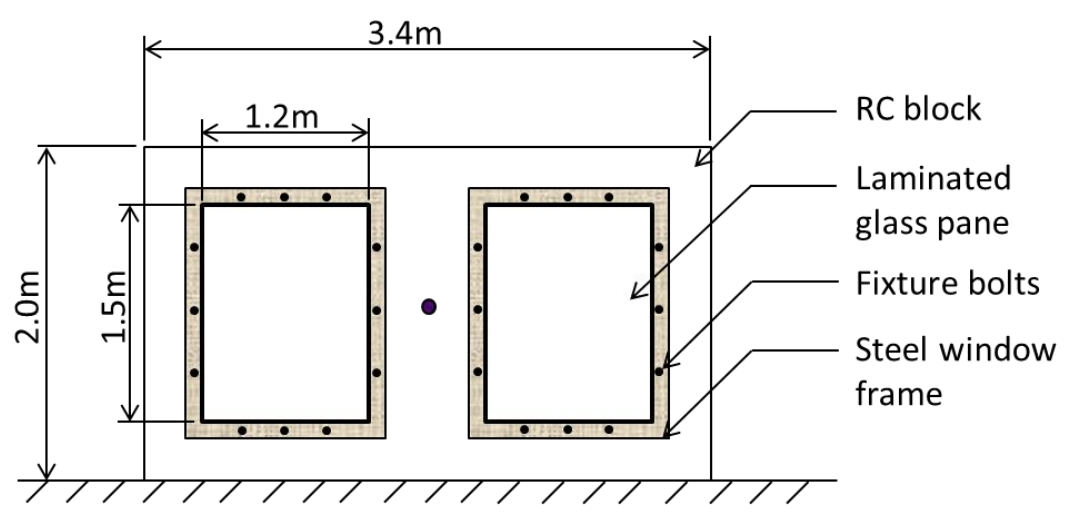

a) Front view
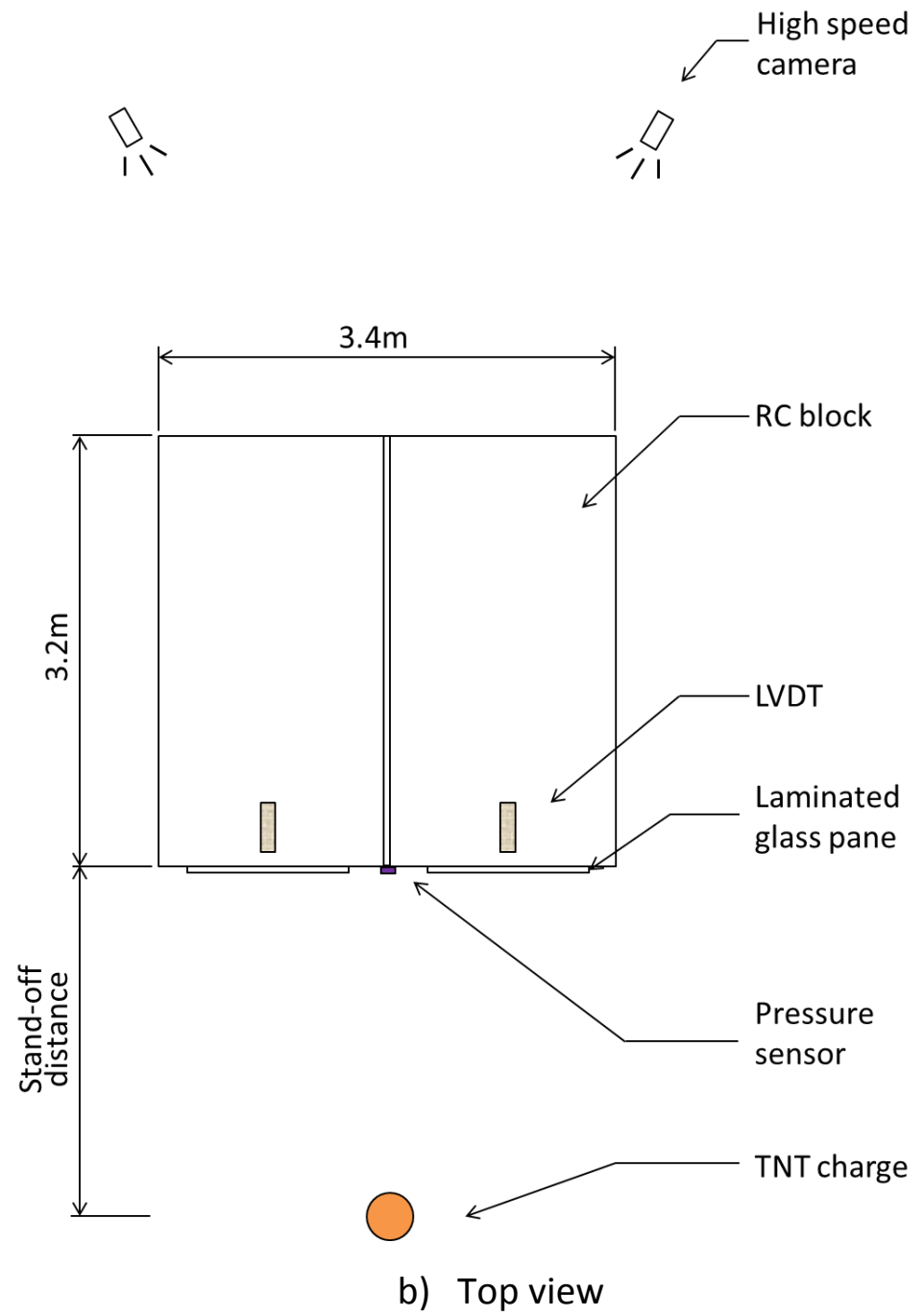

Figure 1 Testing site plan 


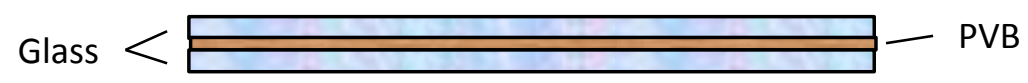

a) Singly laminated glass pane

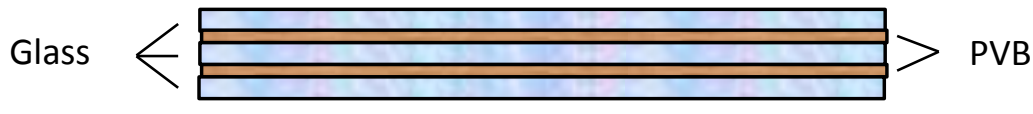

b) doubly laminated glass pane

1

Figure 2 Illustration of window specimens

2 


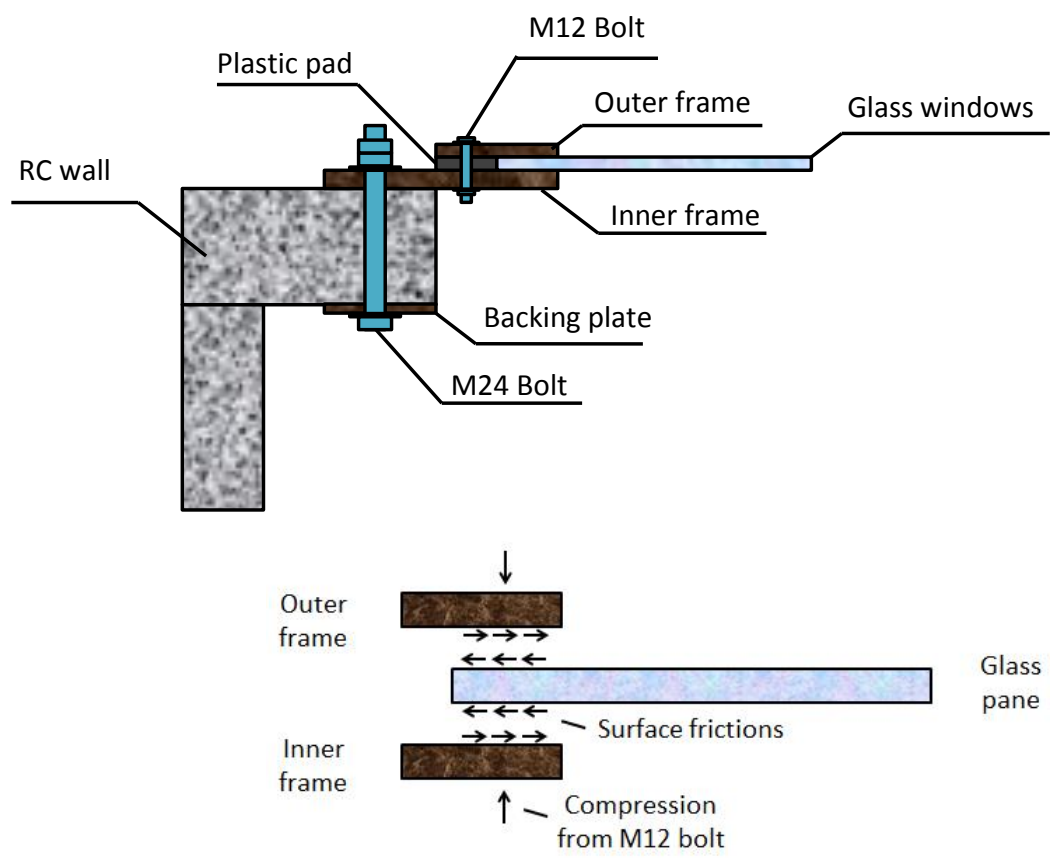

a) Fixed boundary

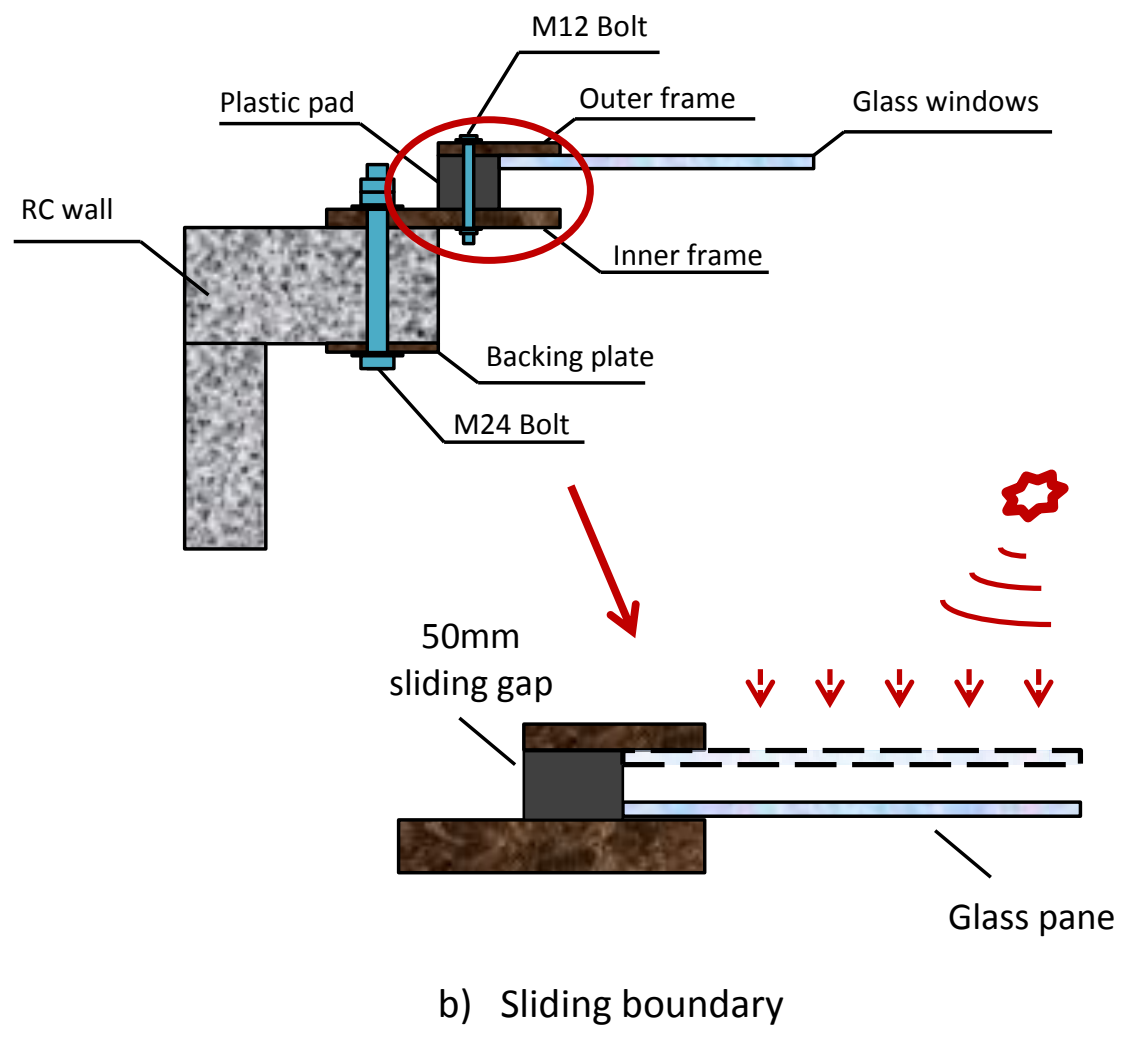




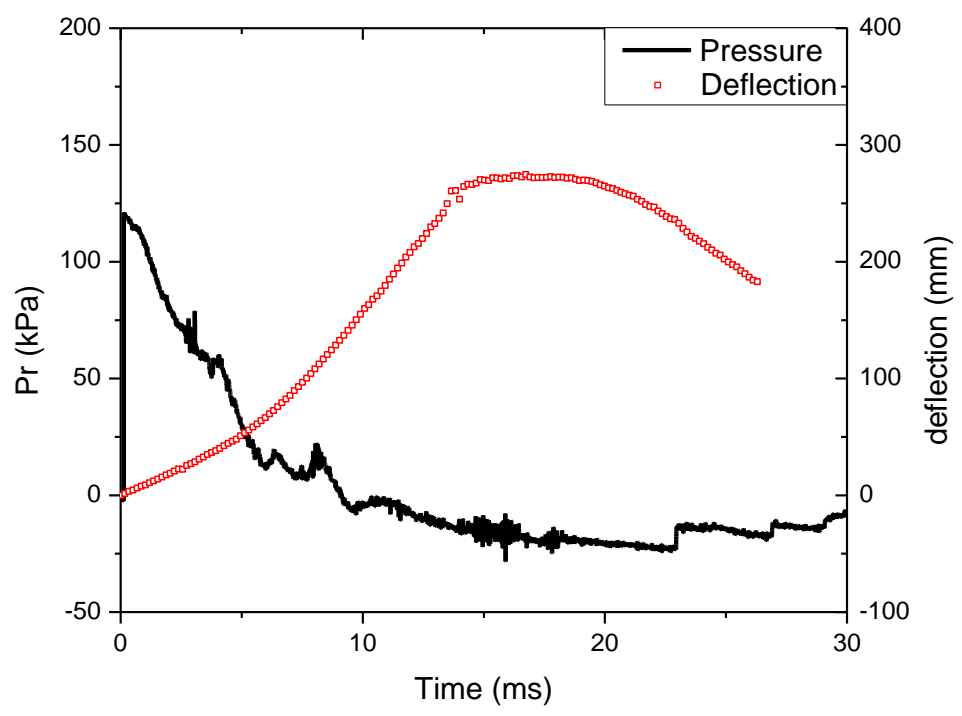

a) Test 1

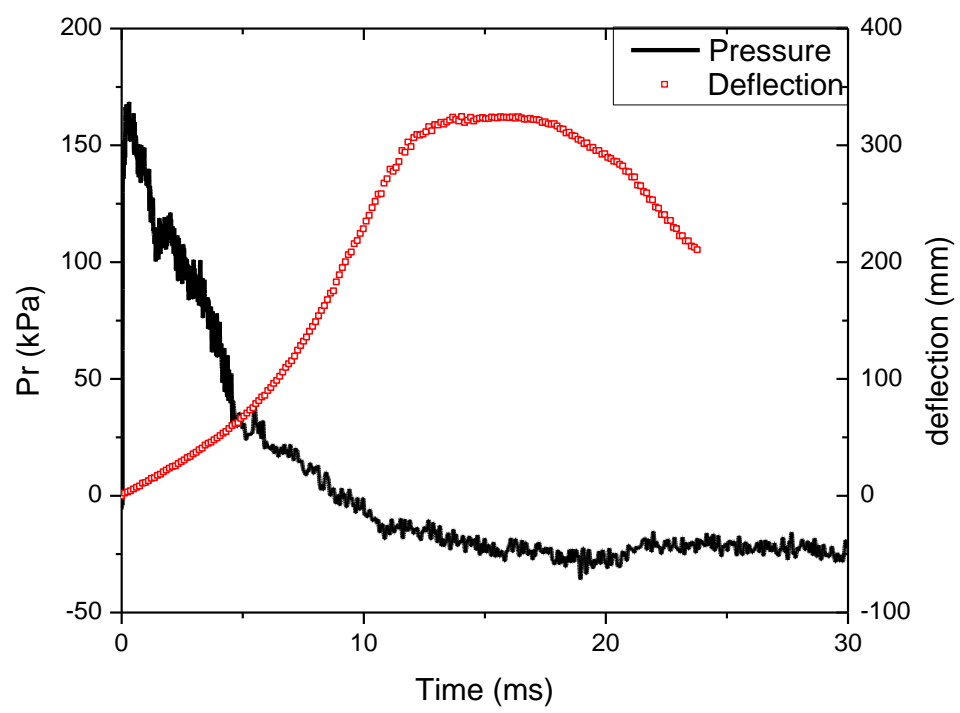

b) Test 2 


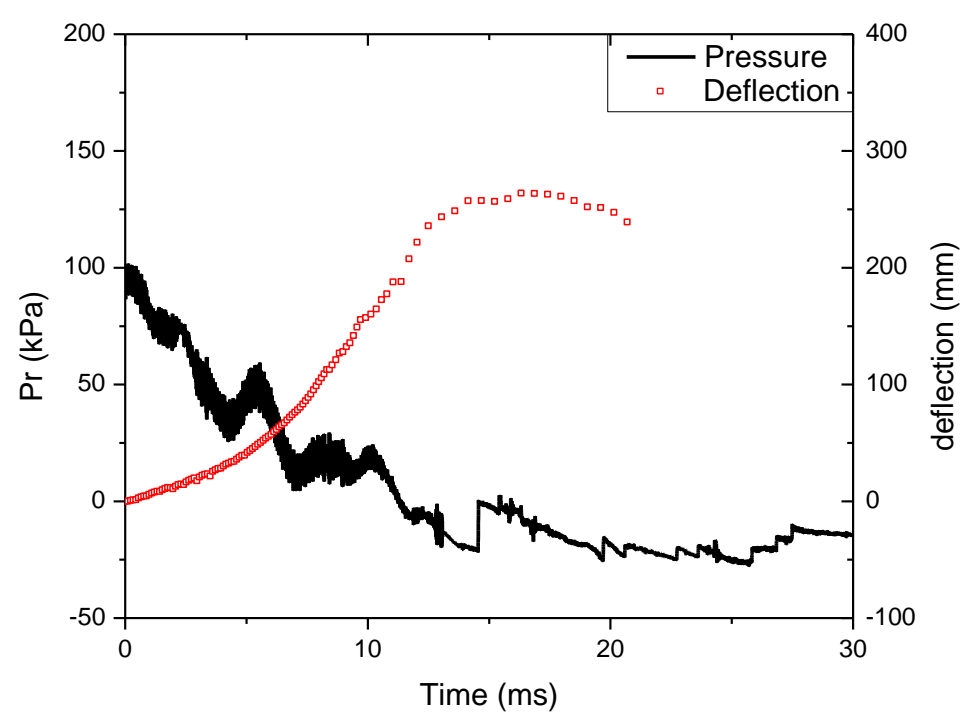

c) Test 3 


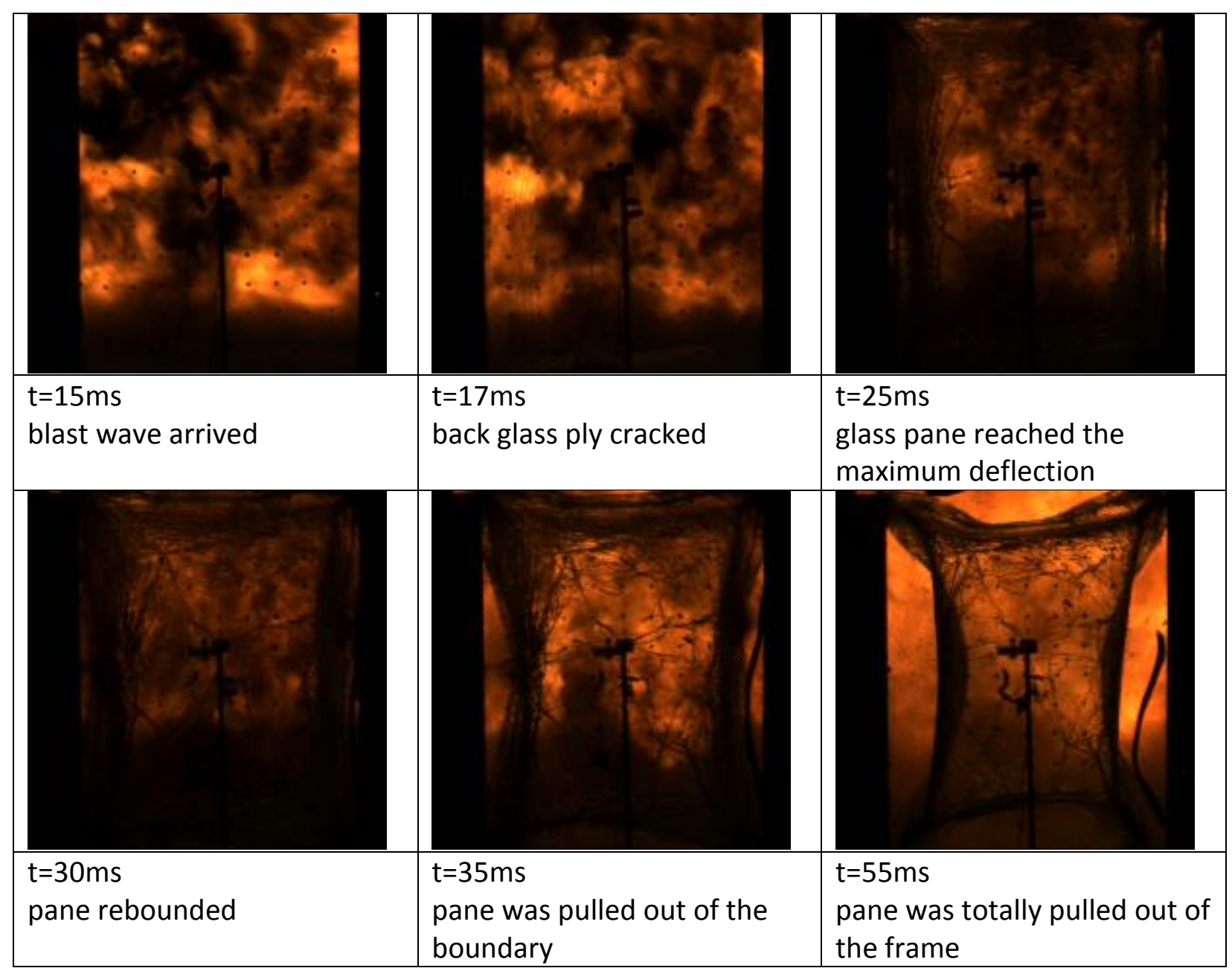

1

a) Pane 4-1-1

2 


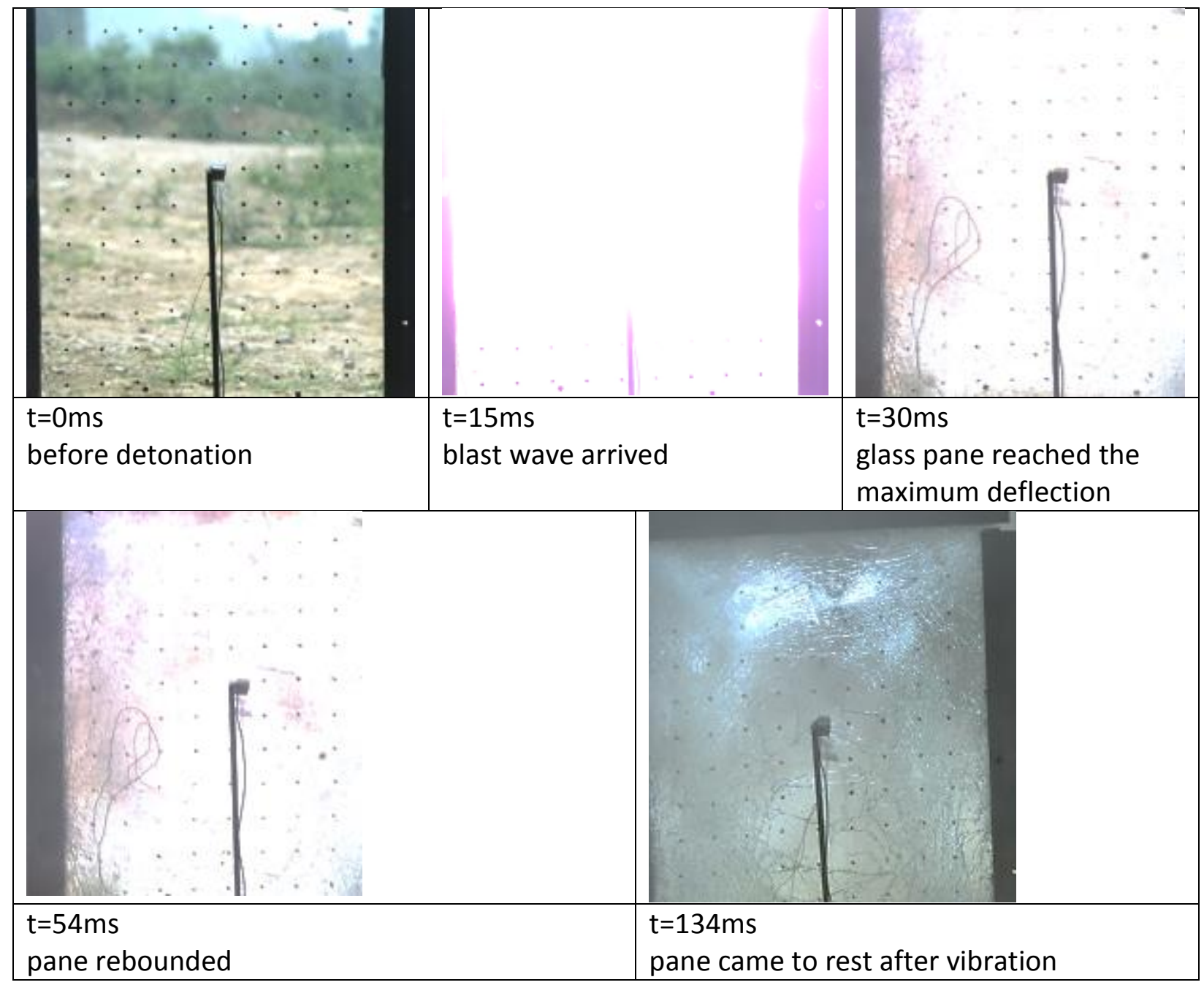

1

b) Pane 1-1-1

2

Figure 5 Snapshots of high-speed images for Pane 4-1-1 and 1-1-1

3 


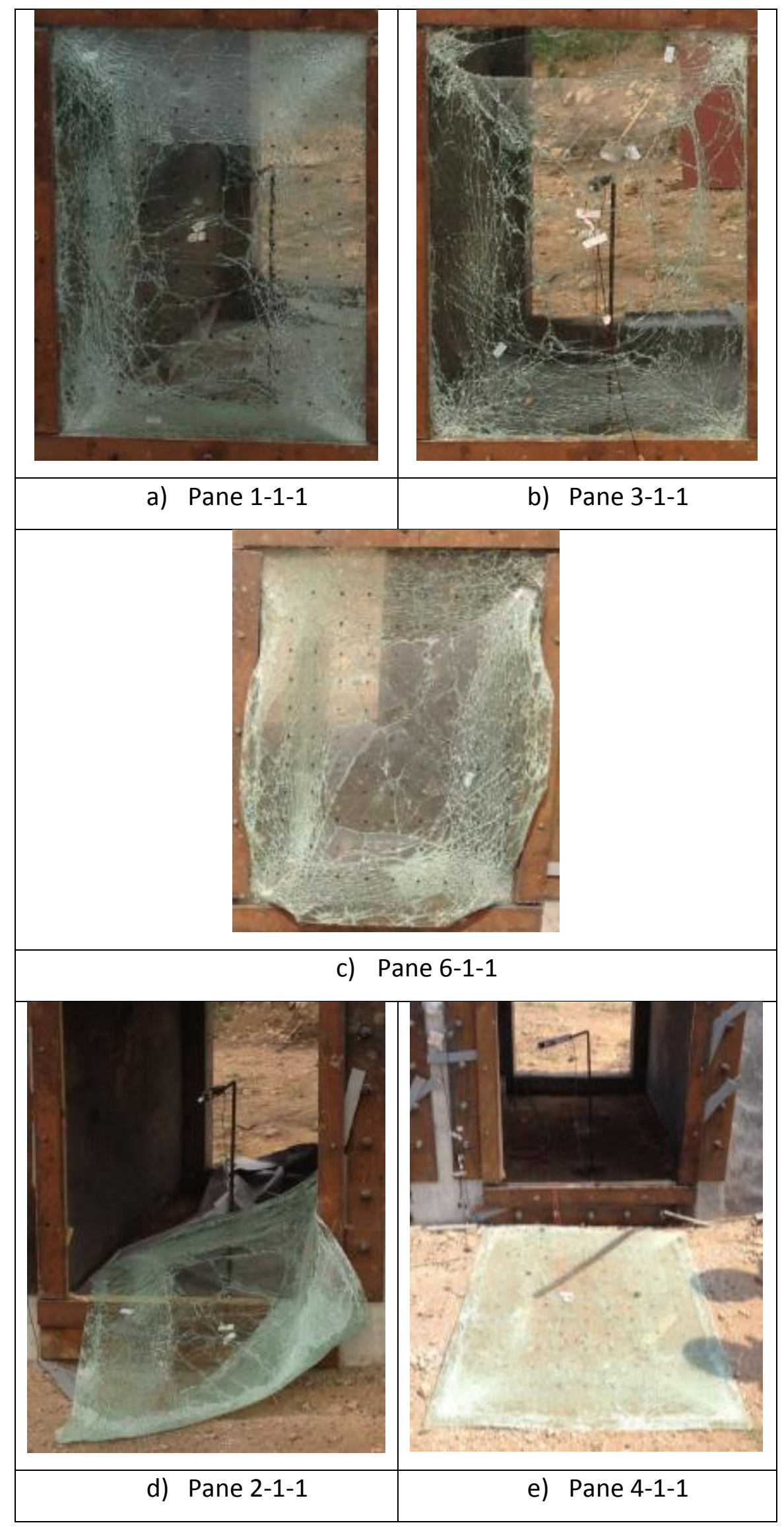

Figure 6 Failure patterns 


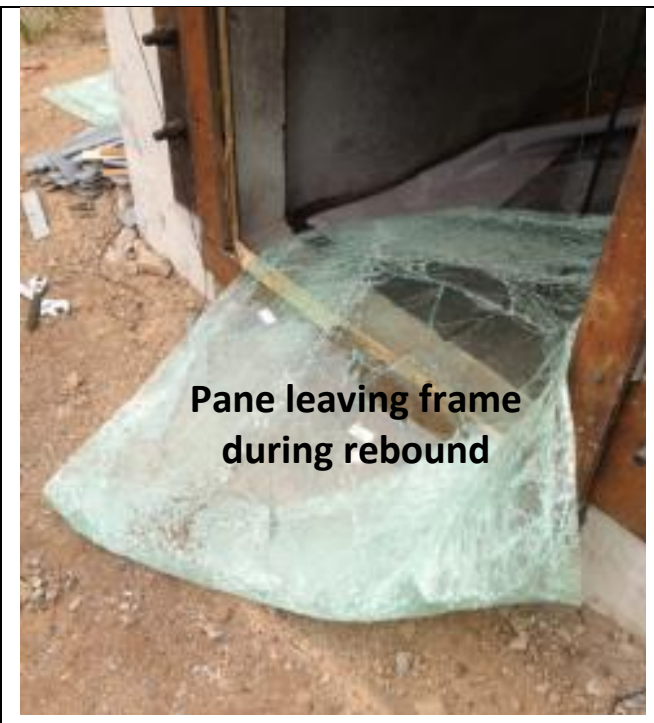

a) $50 \mathrm{~mm}$ bite in Pane 2-1-1 $\left(\mathrm{Pr}^{+}=169 \mathrm{kPa}, \mathrm{Ir}^{+}=476 \mathrm{kPa}-\mathrm{ms}\right)$

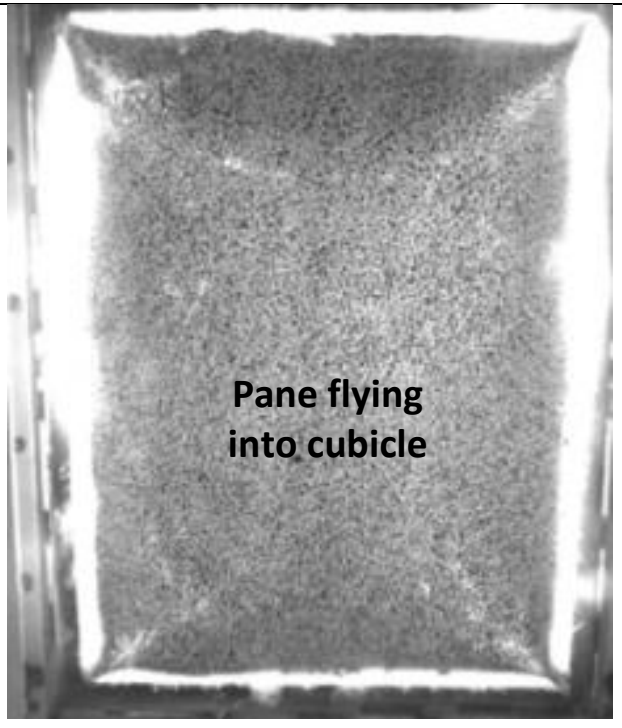

b) $25 \mathrm{~mm}$ bite by Hooper et al. [9] $\left(\mathrm{Pr}^{+}=152 \mathrm{kPa}, \mathrm{Ir}^{+}=461 \mathrm{kPa}-\mathrm{ms}\right)$ 


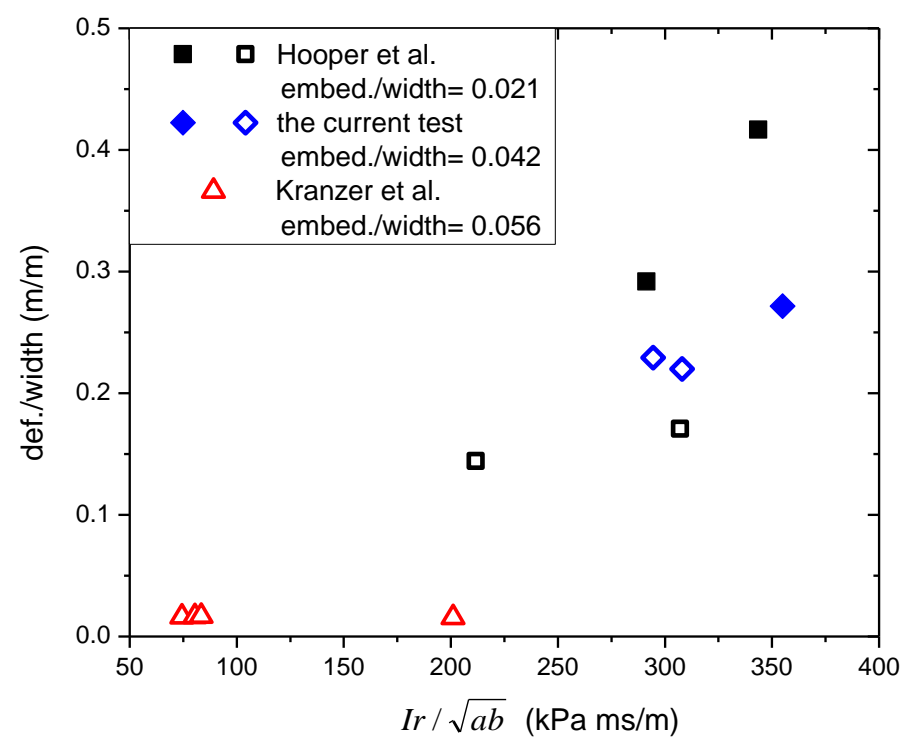

1

2 Note: $a$ and $b$ stand for window length and width; Ir is the reflected impulse.

3

Figure 8 Maximum pane deflections versus bite depth at different reflected impulses

4 


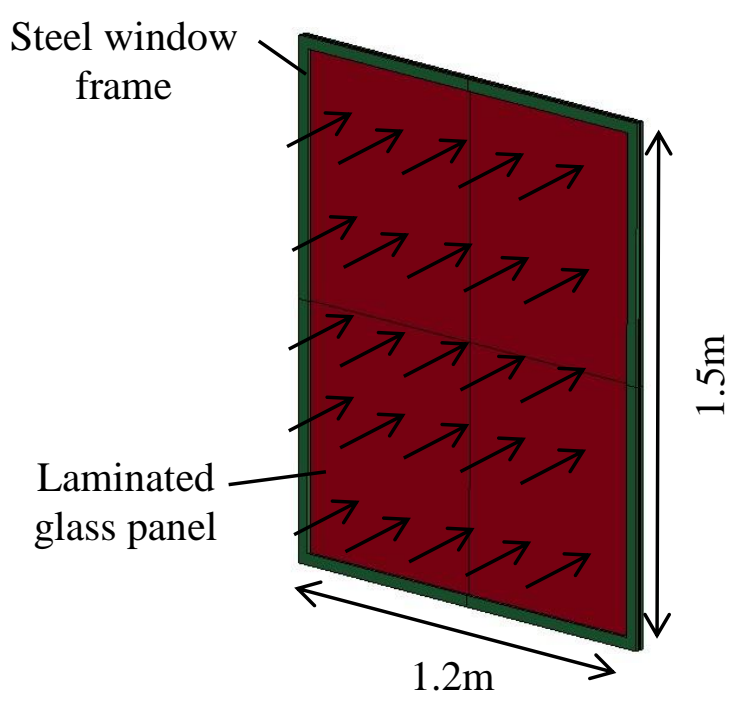

a) Framed glass window without retrofit

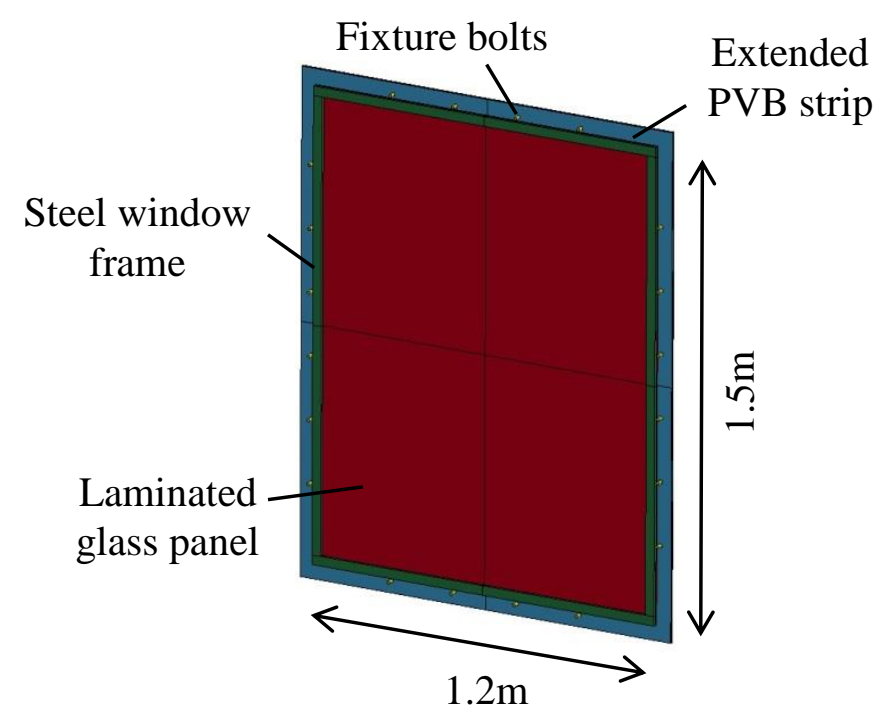

c) Glass window with PVB bolted along boundaries

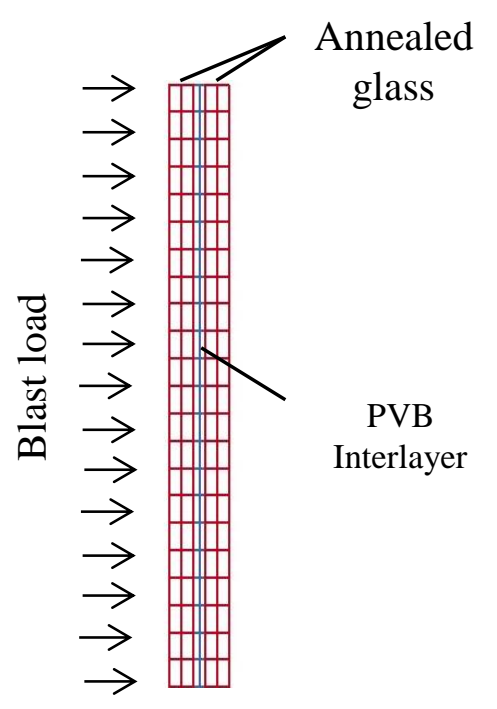

b) Element across the thickness direction

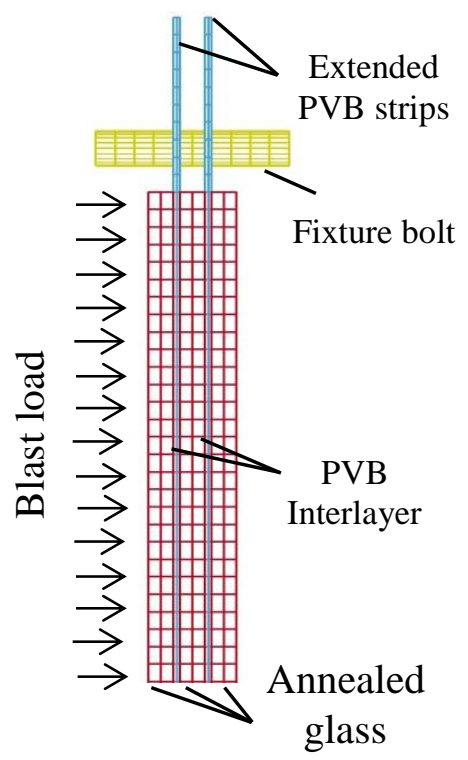

d) Element across the thickness direction 


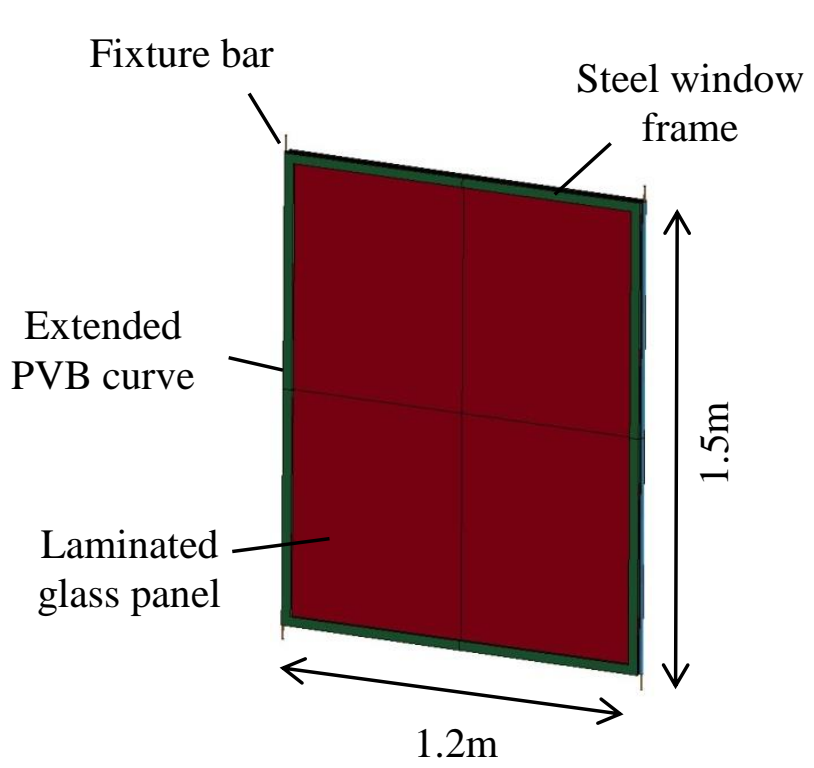

e) Glass window with PVB holded by fixture bars

1

Figure 9 Laminated glass models

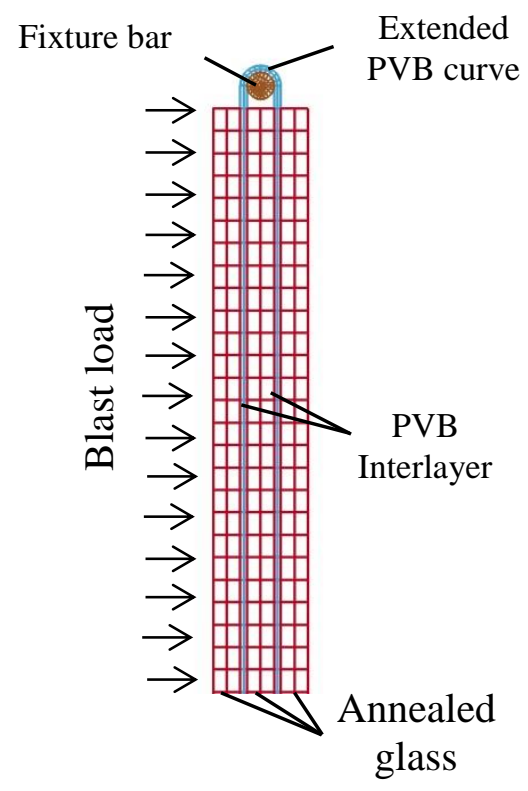

f) Element across the thickness direction

2 


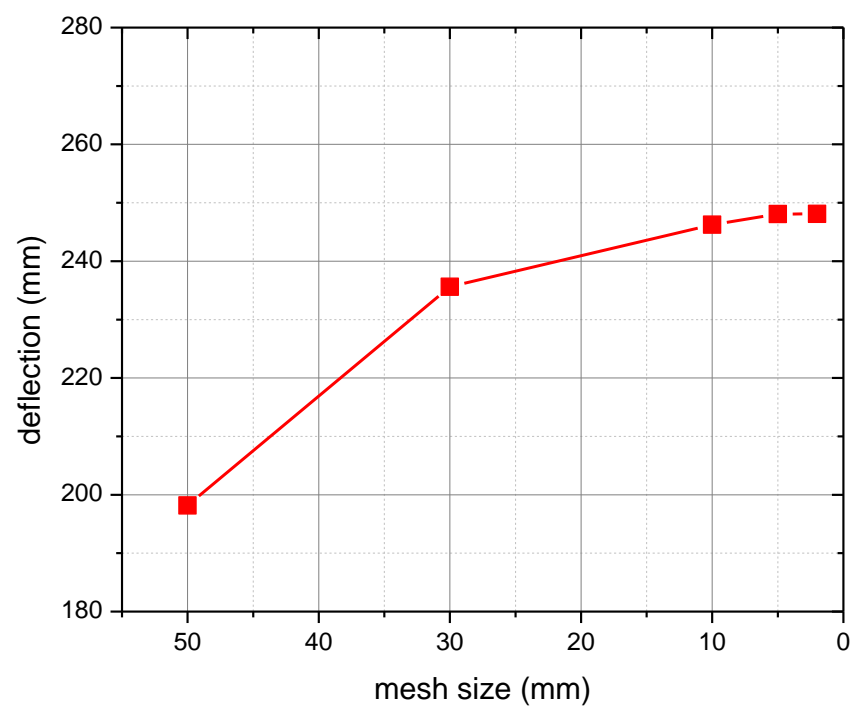

$\frac{1}{2}$

Figure 10 Mesh size sensitivity test

3 


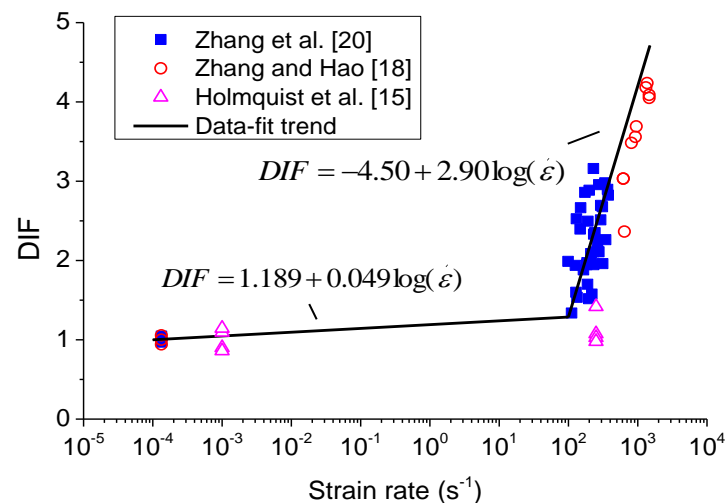

a) Compressive DIFs vs strain rates

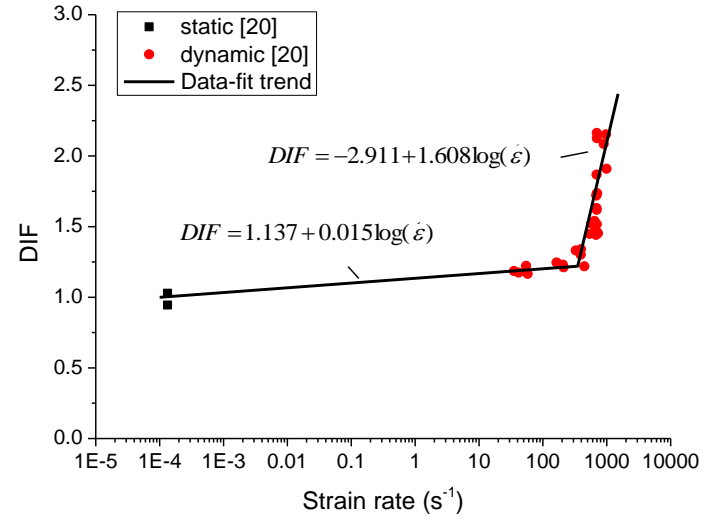

b) Tensile DIFs vs strain rates

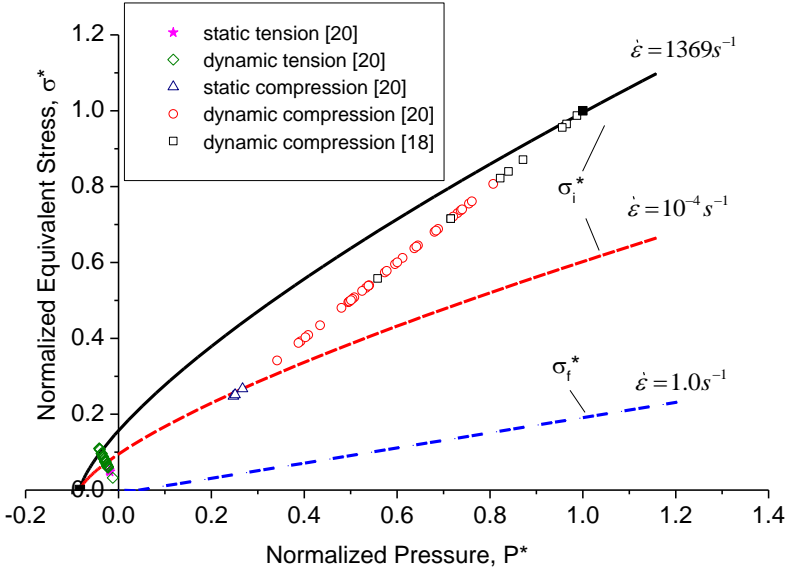

c) Strength model 


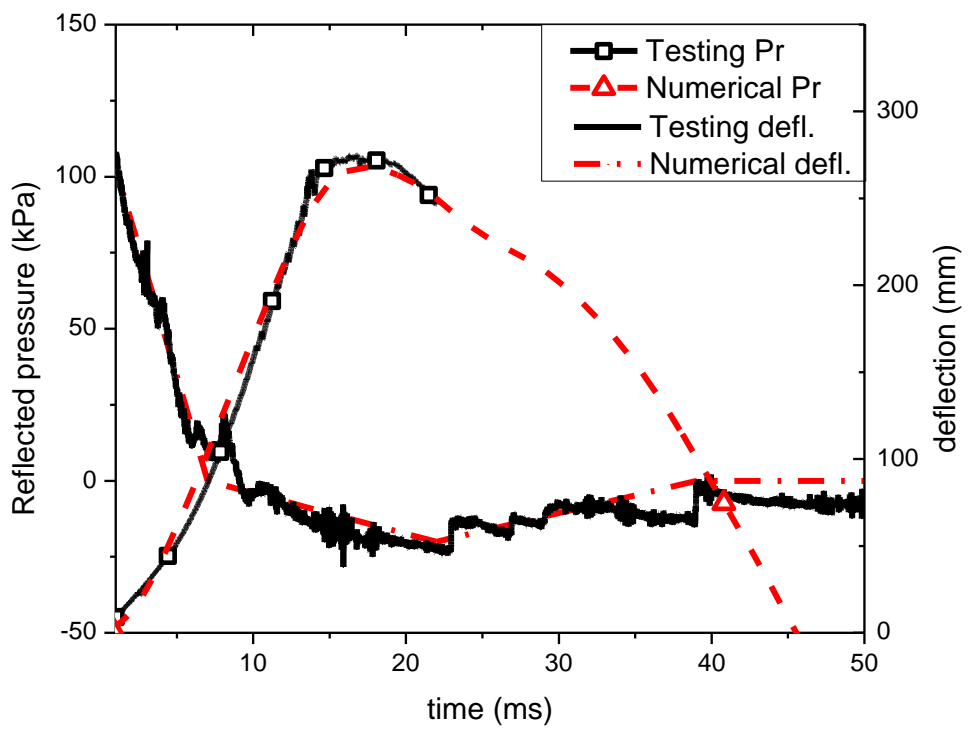

$\frac{1}{2}$

Figure 12 Pressure and central deflection time histories in field test and numerical simulation for Pane 1-1-1 3 


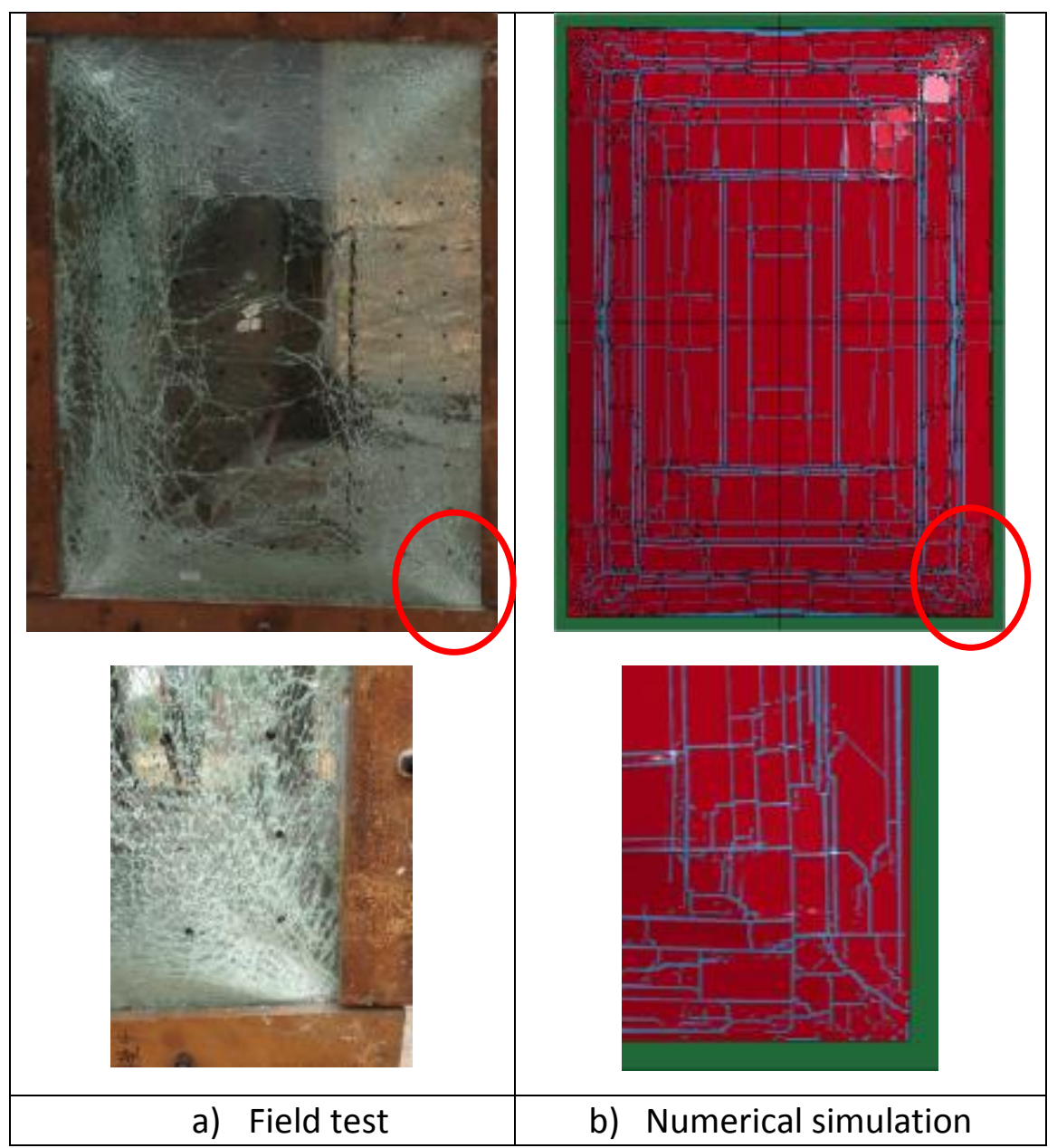

Figure 13 Comparison of failure patterns for pane 1-1-1 


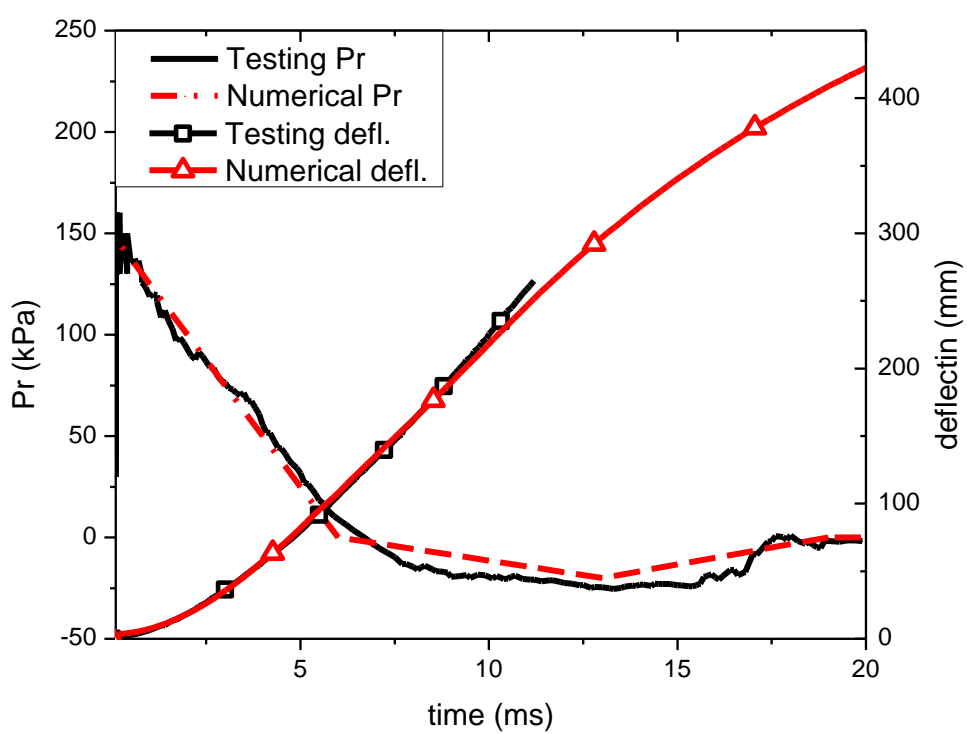

1

2 Figure 14 Pressure and central deflection histories in field test and numerical simulation of Hooper et al.'s test 3 [9] 


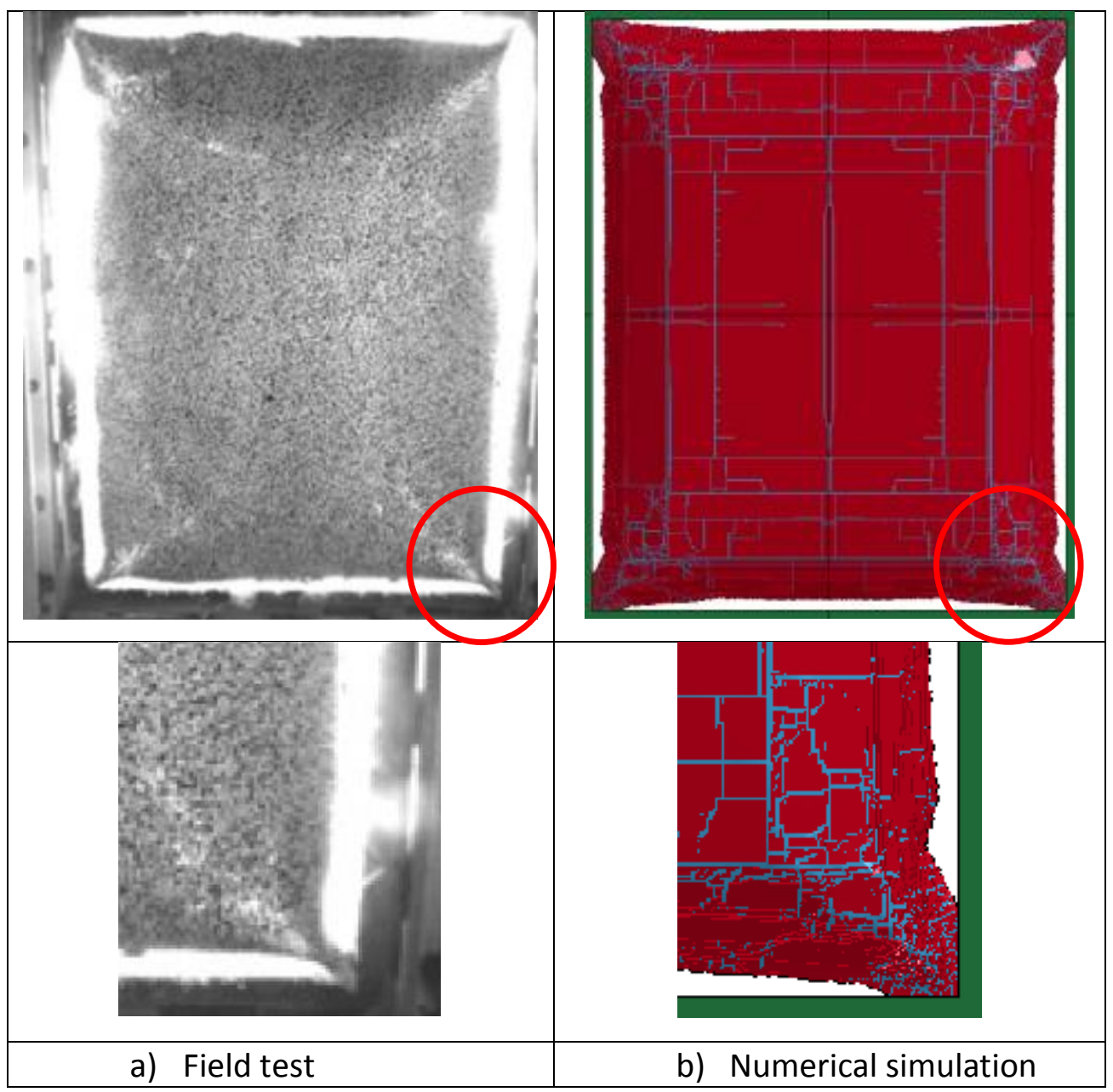

a) Field test

b) Numerical simulation

2 


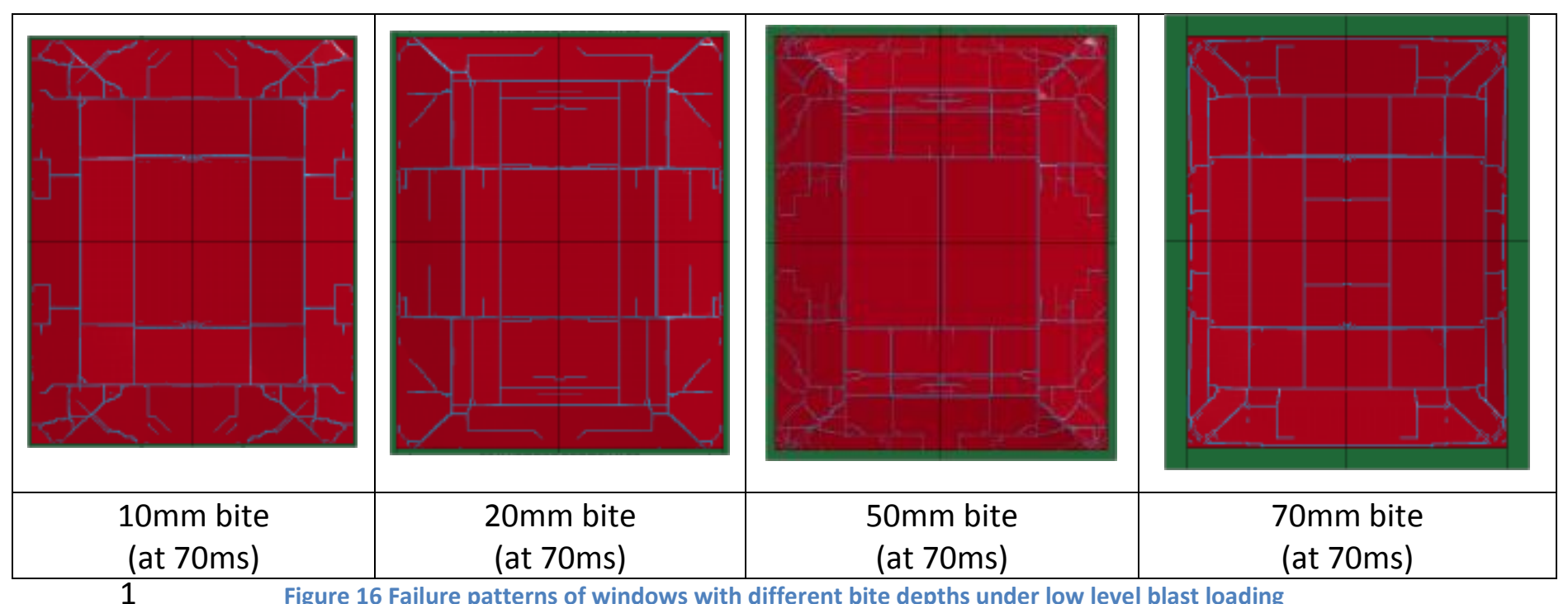

1 Figure 16 Failure patterns of windows with different bite depths under low level blast loading

2 


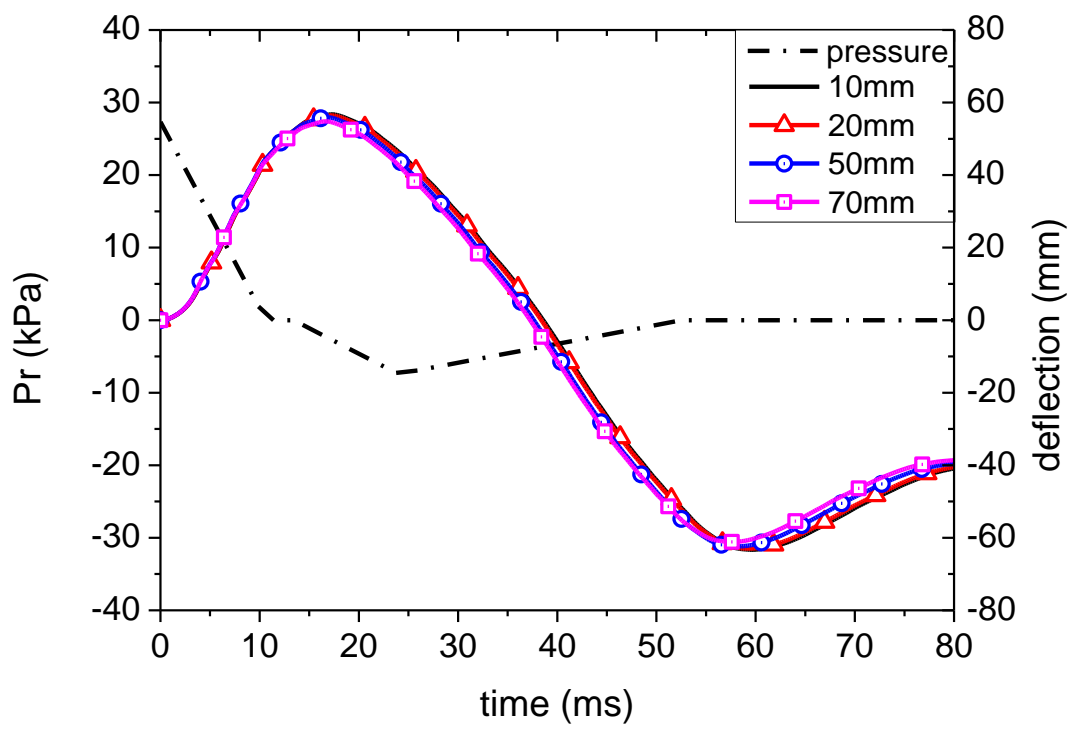

1

Figure 17 Blast load and pane central displacement histories of windows with different bite depths under low level blast loading

4 


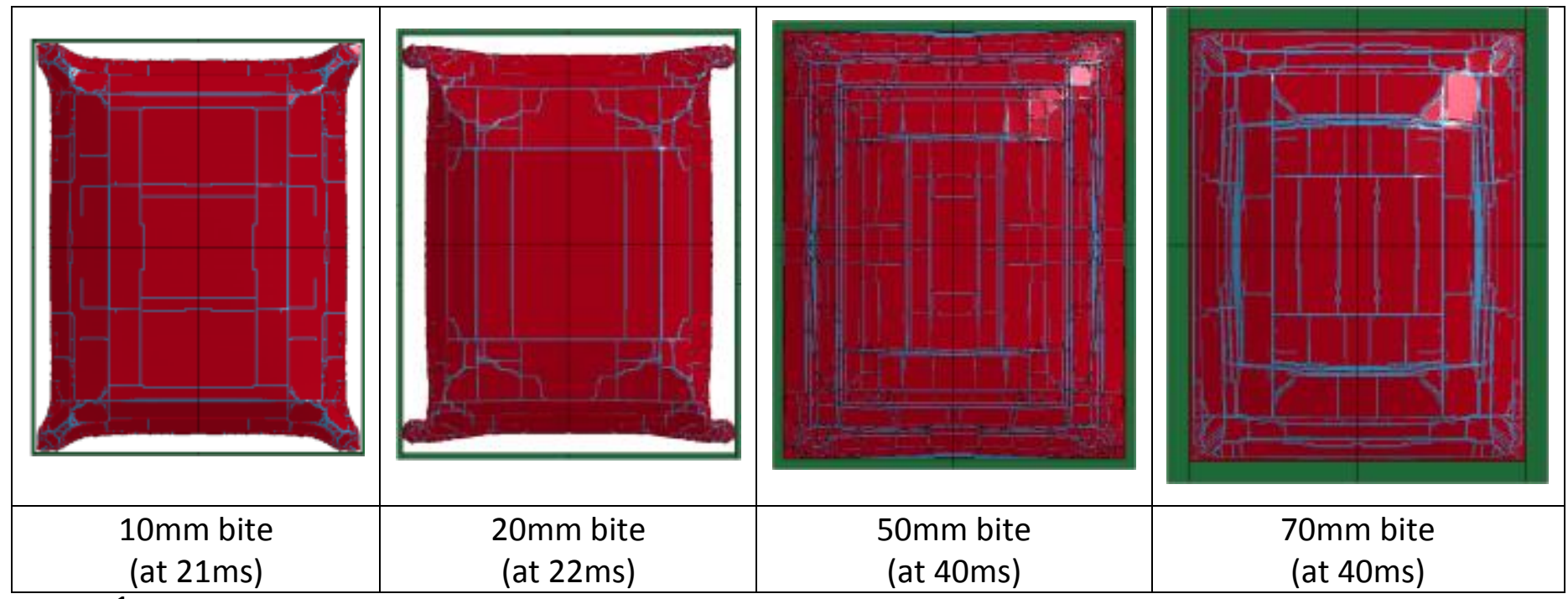

1 Figure 18 Failure patterns of windows with different bite depths under intermediate high level blast loading 2 


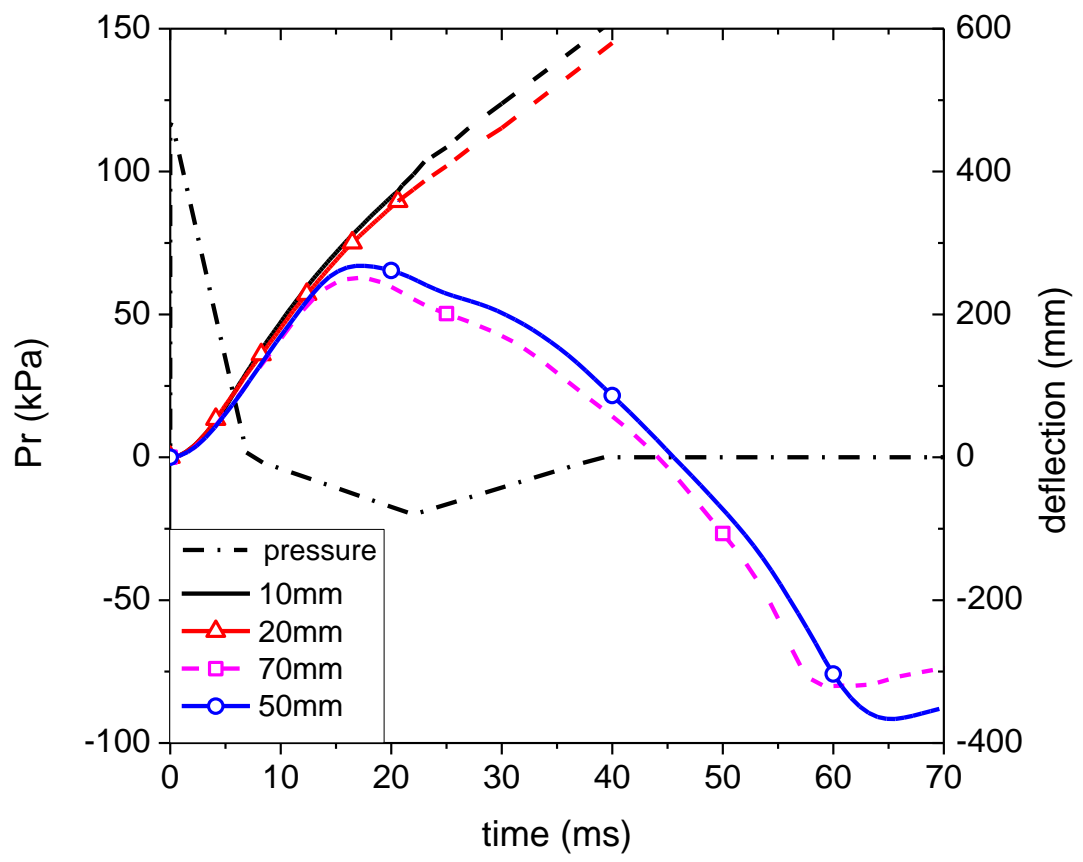

1

Figure 19 Blast load and pane central displacement histories of windows with different bite depths under intermediate high level blast loading 


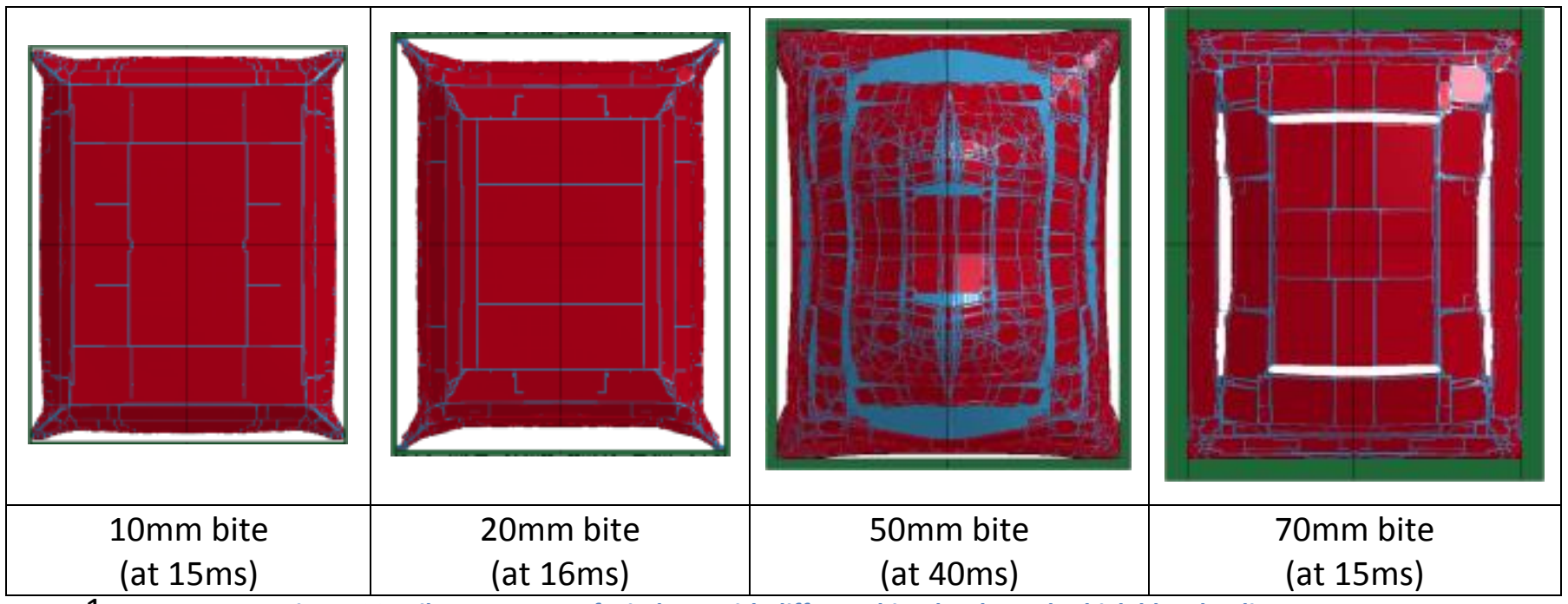

$1 \quad$ Figure 20 Failure patterns of windows with different bite depths under high blast loading

2 


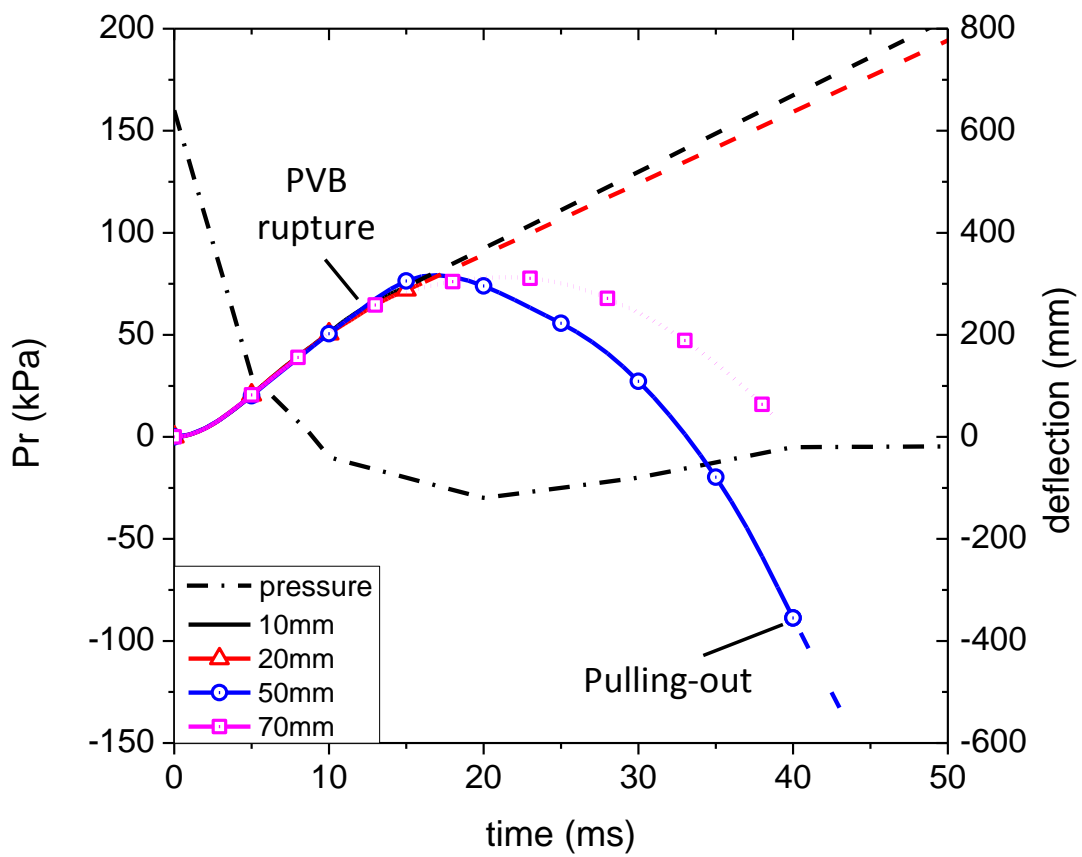

$\frac{1}{2}$
3

Figure 21 Blast load and pane central displacement histories of windows with different bite depths under high blast loading

4 


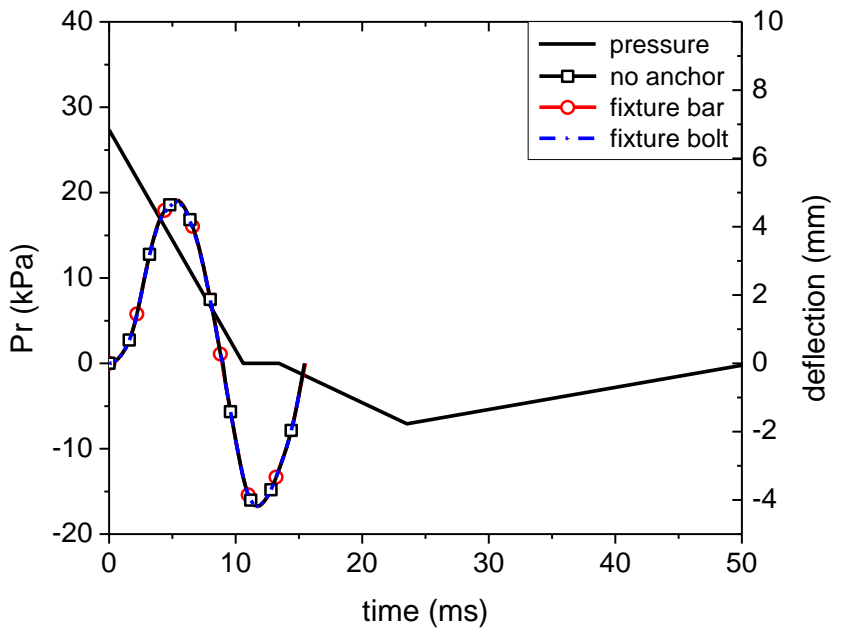

a) Small scale

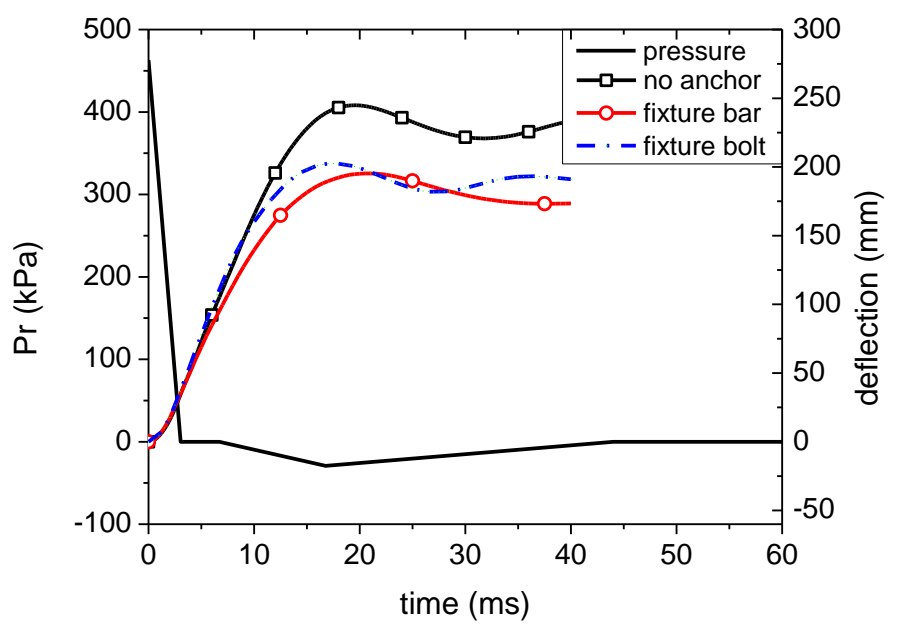

c) Large scale

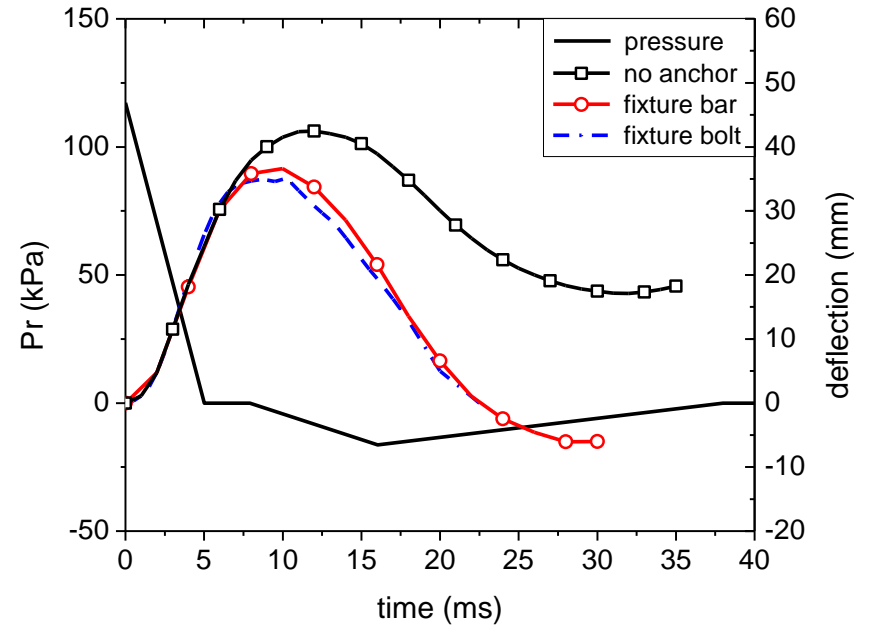

b) Intermediate scale

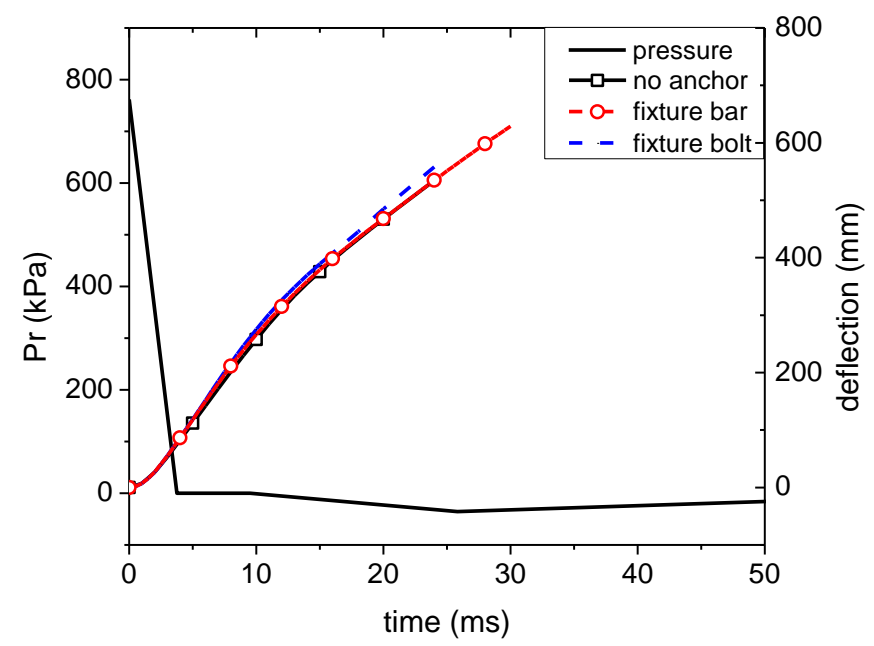

d) Extra-large scale 


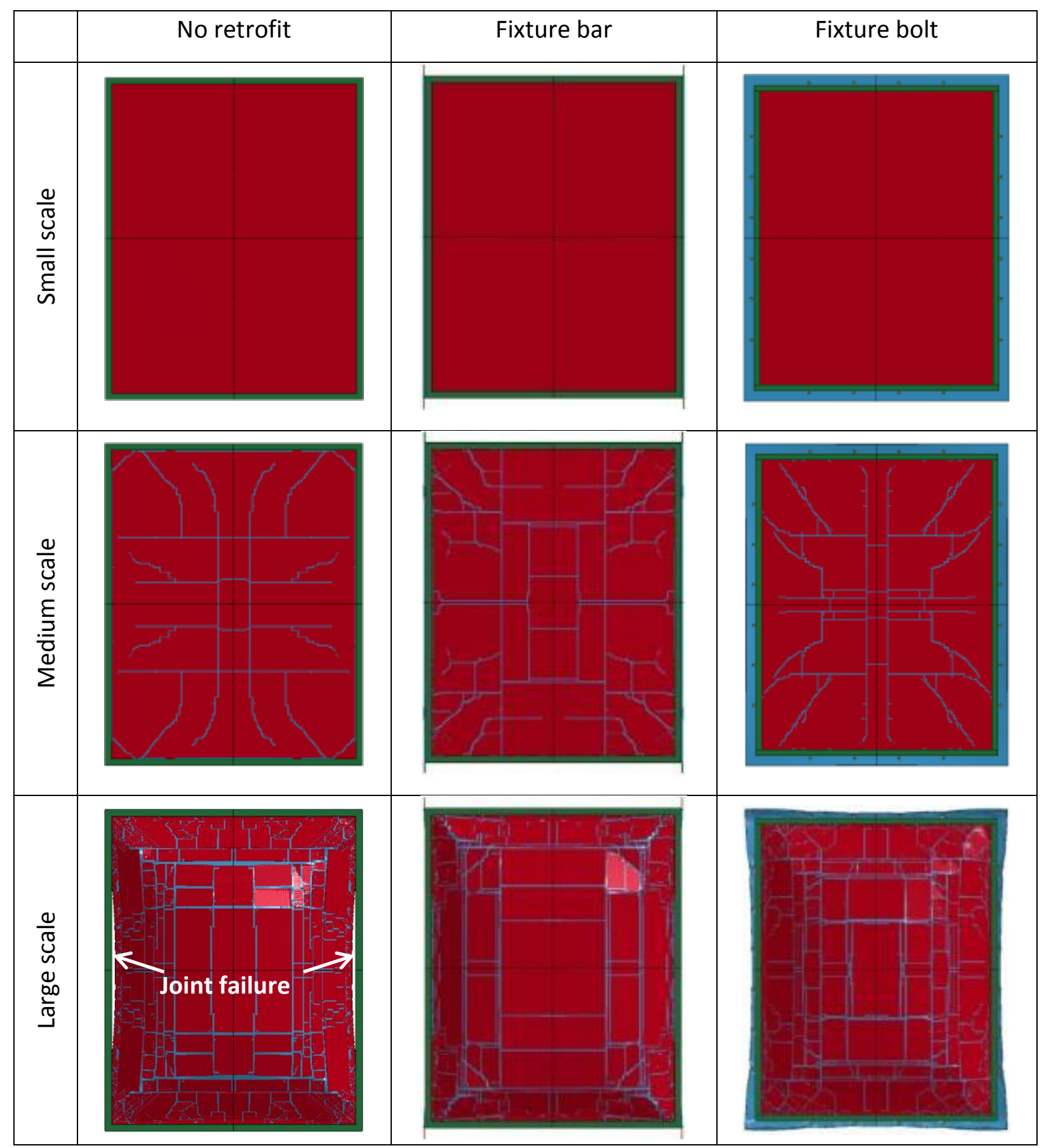




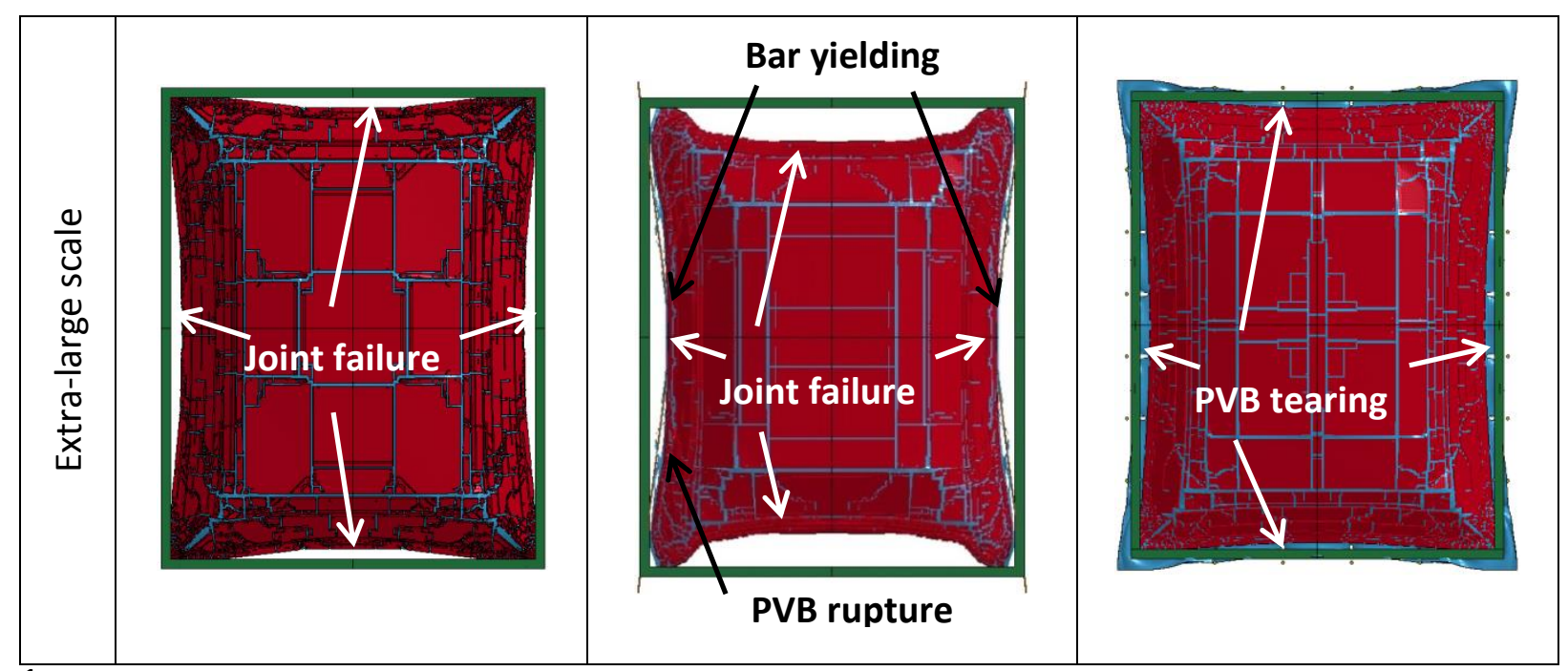

1

Figure 23 Ultimate states of laminated glass windows with different retrofits

2 


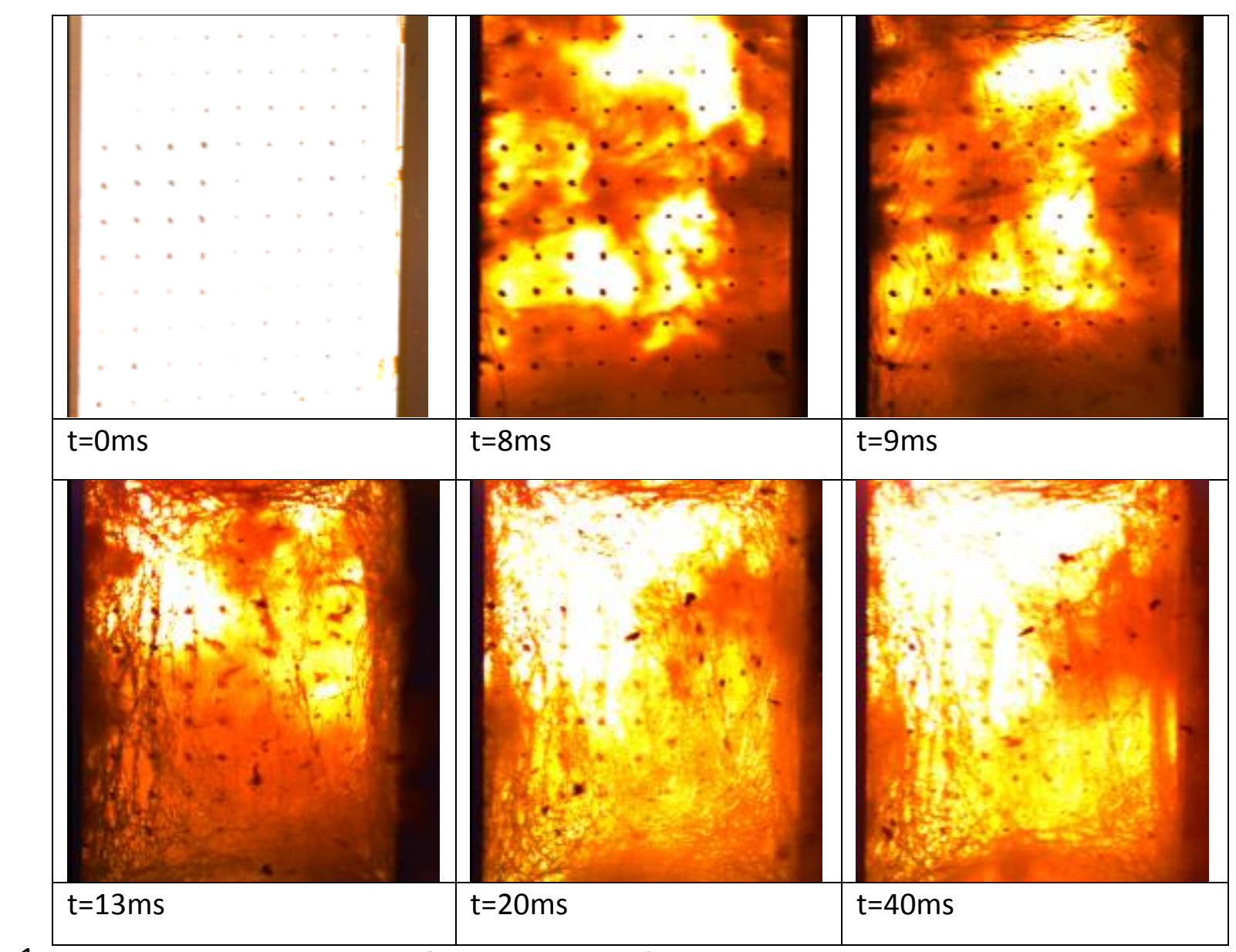
1

Figure 24 Snapshots of high-speed images of the laminated pane with sliding boundary

2 


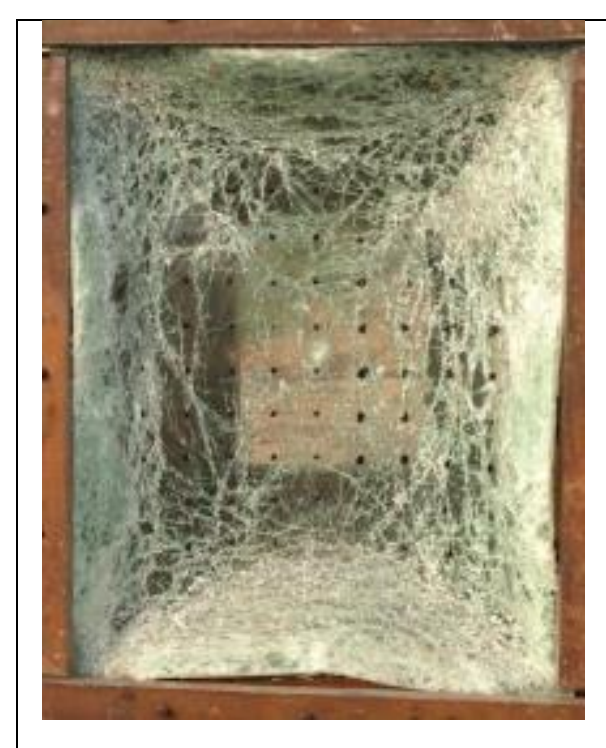

a) Pane 7-1-1 with sliding boundary

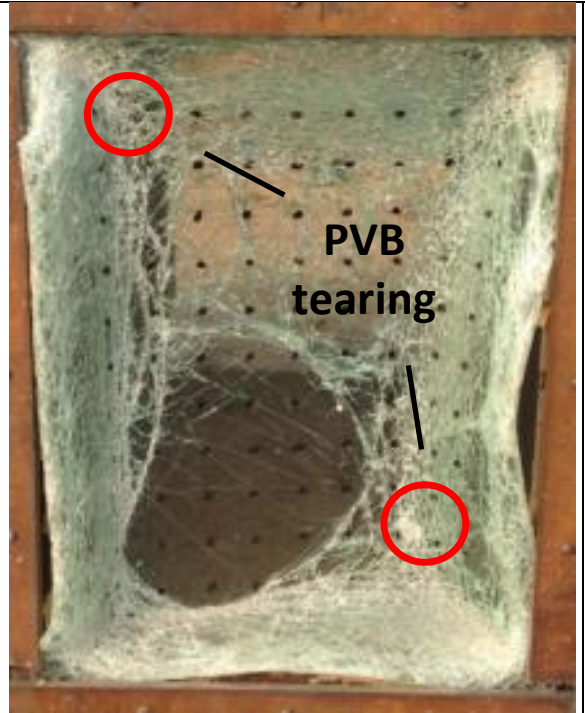

b) Pane 7-1-2 with fully fixed boundary

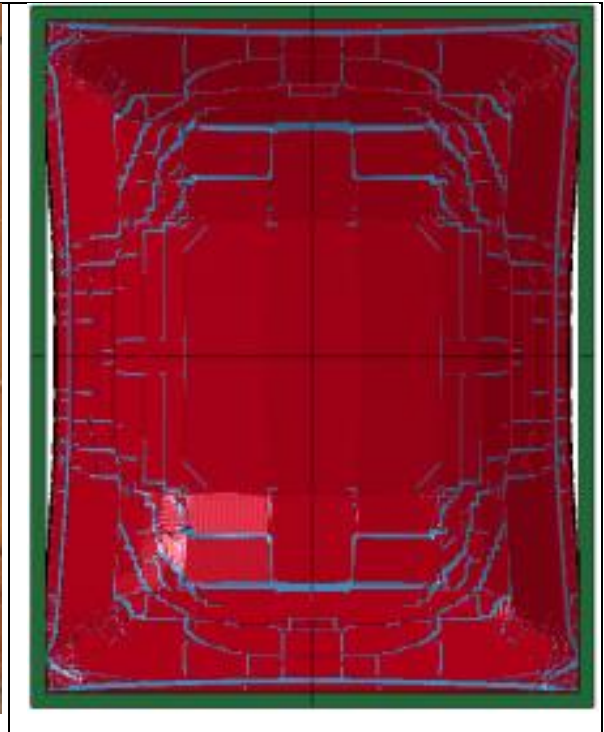

c) Pane 7-1-2 numerical model with fully fixed boundary

Figure 25 Failure patterns of the laminated panes in test 7

2 


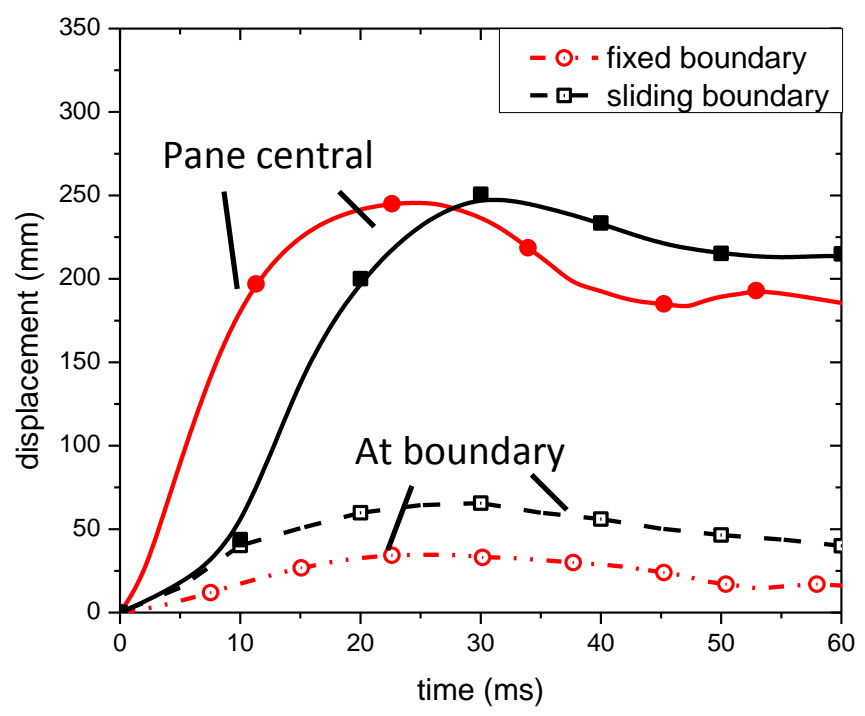

Figure 26 Comparison of displacement histories of test 7 